\title{
ENDOGENOUS CHILDLESSNESS AND STAGES OF DEVELOPMENT
}

\author{
Thomas Baudin \\ IÉSEG School of Management \\ (LEM UMR 9221)
}

\section{Paula Gobbi}

ECARES, Université libre de Bruxelles

\author{
David de la Croix \\ IRES, Université catholique de Louvain
}

\begin{abstract}
Although developing countries are characterized by high average fertility rates, they are as concerned by childlessness as developed countries. Beyond natural sterility, there are two main types of childlessness: one driven by poverty and another by the high opportunity cost of child-rearing. We measure the importance of the components of childlessness with a structural model of fertility and marriage. Deep parameters are identified using census data from 36 developing countries. As average education increases, poverty-driven childlessness first decreases to a minimum, and then the opportunity-driven part of childlessness increases. We show that neglecting the endogenous response of marriage and childlessness may lead to a poor understanding of the impact that social progress, such as universal primary education, may have on completed fertility. The same holds for family planning, closing the gender pay gap, and the eradication of child mortality. (JEL: J11; O11; O40)
\end{abstract}

\section{Introduction}

When analyzing population dynamics and fertility in developing countries, researchers as well as international organizations focus on aggregate measures like population growth rates or the average number of children per woman. Nothing is said about

The editor in charge of this paper was M. Daniele Paserman.

Acknowledgments: We thank three anonymous referees, M. Bailey, A. Rijpma, H. Strulik, and participants to conferences in Clermond-Ferrand, Iowa city, Paris, and Utrecht, and to seminars at IFPRI (Washington), Simon Fraser (Vancouver), Leuven (Belgium), University of Kent, University of Washington, University of Oregon, Bocconi University, Copenhagen Business School, University of Mannheim, University of Konstanz, Free University of Brussels, and Tinbergen Institute for their comments on an earlier draft. Computational resources were provided by the supercomputing facilities of the Université catholique de Louvain (CISM/UCL). This research is part of the ARC project 15/19-063 on "Family Transformations" (French speaking community of Belgium). de la Croix is a Research Fellow at CEPR. Gobbi is a Research Affiliate at CEPR.

E-mail: t.baudin@ieseg.fr (Baudin); david.delacroix@uclouvain.be (de la Croix); pgobbi@ulb.ac.be (Gobbi) 
childlessness. ${ }^{1}$ This gives the impression that women from developing countries always have (many) children, which is far from reality. For instance, in 2005 in Cameroon, which belongs to what has been labeled the African Infertility Belt, $17.8 \%$ of women aged between 40 and 54 were childless. These percentages are comparable to those prevailing in developed countries like Australia (16\% in 2011), Sweden (13.4\% in 2010), and the United States (18.8\% in 2010) for women between 40 and 44 years old. ${ }^{2}$ Our paper strongly nuances the idea that, in developing countries, women have high fertility rates; what we show is that those women who do have children have many on average, but that many women might not have any children at all.

The small amount of research on childlessness in these countries is even more surprising when observing that childlessness is very much caused by poverty. This can arise through different channels. Venereal diseases and pregnancy-related infections are the most common cause of infertility in developing countries. Malnutrition, lower chances of finding a stable partner, and higher mortality rates also play a role. Following the theory of capabilities by Sen and Nussbaum (1993), this cause of childlessness deteriorates poor people's capability sets. Eradicating this kind of childlessness should then be on policy makers' agendas. Moreover, the presence of this poverty-driven childlessness may make total fertility increase with the standard of living (as found by Vogl 2016 for some poor countries), hence making the demographic transition happen only once a relatively high income or education threshold has been reached. ${ }^{3}$ Belsey (1976) shows that childlessness can be as high as $40 \%$ for a given cohort of women in some regions or tribes of Sub-Saharan Africa. The presence of high levels of childlessness among the poor has also been evidenced in other studies such as Romaniuk (1980), Retel-Laurentin (1974), Poston et al. (1985), Ombelet et al. (2008), Wolowyna (1977), and McFalls (1979). Frank (1983) estimates that, in Africa, 60\% of the variation in total fertility was due to infertility and that a disappearance of pathological infertility could make total fertility increase significantly.

When a country takes off, poverty recedes, and a smaller share of its inhabitants is affected by subfecundity factors leading to childlessness. When it develops further, the opportunity cost of raising children in terms of foregone labor income rises, and more citizens do not have children. The decreasing poverty-driven childlessness rates due to economic development seem to delay the demographic transition predicted by a model that only takes the intensive margin of fertility into account. Understanding the roots of childlessness in high fertility environments, that of developing countries, is the first objective of this paper. This is important for our second objective: evaluating the demographic impact of social progress due to development when accounting for the variations in childlessness rates.

1. See for instance the influential contributions of Pritchett (1994a), Bongaarts (1994a), Ezeh, Bongaarts, and Mberu (2012), and Bongaarts and Casterline (2013), as well as the successive versions of the World Population Policies reports by the United Nations.

2. Data for developed countries come from the OECD Family Database and from IPUMS International for Cameroon.

3. This type of childlessness is a Malthusian check, not mentioned in Malthus (1798). 
One major limit of the existing studies on childlessness resides in the impossibility of measuring poverty-driven childlessness in the data. ${ }^{4}$ In this paper, we provide a unified model of marriage, childlessness, and fertility whose deep parameters are identified using census data from 36 developing countries. This model allows us to quantify the proportion of women who are childless due to different reasons. It extends the model proposed by Baudin et al. (2015) in order to take into account some specificities of fertility decisions in developing countries. These specificities are unwanted births and child mortality, both being somehow endemic in many countries that are not necessarily located in Sub-Saharan Africa. The data are also indicative of assortative matching on the marriage market, a reality we also incorporate into the new framework as childlessness and marital decisions have to be considered together. On average, $9.5 \%$ of women are childless; half of them are married whereas the other half were never married, but only $5 \%$ of married women are childless, compared to around $50 \%$ of single women who are. ${ }^{5}$ This is indicative that the reasons leading to childlessness can be very different within both populations. Understanding the determinants of childlessness within both populations is thus crucial, but understanding childlessness at the aggregate level cannot be done without understanding the determinants of marriage decisions. To the best of our knowledge, our contribution is the first to explore how childlessness and fertility adjust to development taking all these elements into account.

More precisely, we distinguish between four types of childlessness. First, opportunity-driven childlessness stems from the time cost of having children: a highly educated woman earns high wages and thus faces a high opportunity cost when she is not at work (see also Gobbi 2013; Aaronson et al. 2014 on this type of childlessness). Natural sterility refers to the innate biological impossibility of having children, which does not depend on the level of education or wealth. The two remaining types of childlessness are driven either by poverty or by mortality. Poverty-driven childlessness concerns low-educated women and more specifically singles for whom the poverty burden is the heaviest. For some couples, even though becoming parents is economically feasible, it can only be done at the cost of impoverishing the couple too much. Finally, mortality-driven childlessness arises when no newborn children survive.

4. Censuses never ask childless people why they are childless. Alternative data sets, like the National Survey for Family Growth in the United States, provide details on people's reproductive behavior and motivation. However, these data sets contain a limited number of observations and a significant number of people provide contradictory answers, preventing analysts from determining the nature of childlessness. Demographic and Health Surveys ask women about the ideal number of children they would have liked to have in their lifetime irrespective of their actual number. One could consider that poor childless women who answer a positive number are childless due to poverty. However, there is no guarantee that the absence of children in their lifetime is not the result of a decision due to career or matrimonial perspectives rather than a poverty constraint.

5. This is indicative that childlessness is not a phenomenon that comes from celibacy only. "Spinsters" as evoked by the literature account for only one-half of childlessness and many of them are not childless. Definitive celibacy and induced childlessness were a way to regulate fertility in early Western Europe, as shown by Lesthaeghe (2015) and Olwen (1984). 
Our theory allows assessing whether endogenous childlessness and marriage are important when one wants to measure the impact of development on fertility in the long run. The social progress due to development that we study is: primary education for all, no child mortality, perfect family planning, and gender equality on the labor market. Unlike the existing economic literature, our framework allows us to analyze the impact of each social change on the two (intensive and extensive) margins of fertility (i.e., the fertility of mothers and motherhood rates).

Imposing primary education generally reduces the average fertility of mothers automatically, as fertility is a decreasing function of education for both single and married women. This effect is however partly compensated by the effects on marriage and childlessness. Poverty-driven childlessness declines, which goes against the initial dampening effect on fertility. On the whole, the drop in childlessness makes the effect of a generalization of primary education less fertility-reducing than might be expected on the basis of the intensive margin only.

Together with health policies, family planning is often seen as the workhorse of development policies; May (2012) estimates that giving access to contraceptives reduces fertility by between 0.5 and 1.5 children. In our framework, when women have full control over their fertility, there is less uncertainty concerning the outcome of marriage. This affects marriage rates positively, especially among low-educated women for whom the risk of having unwanted births is the greatest. The rise in marriage rates then reduces the proportion of childless women, which hampers the expected negative effect of family planning on overall fertility rates. We predict that imposing a perfect family planning technology reduces fertility by 0.52 children, at the lower bound of May's prediction.

The effect of an eradication of child mortality on fertility rates also operates through adjustments on the marriage market. Keeping the risk of unwanted births constant, eradicating child mortality increases the uncertainty related to the fertility outcome of marriage. This reduces the incentives to marry, in particular among loweducated women who will then more likely be single and hence childless because of poverty. This highlights a Malthusian type of mechanism pertaining to how mortality allows regulating fertility. On the whole, we find that improving child survival has the expected positive but weak impact on net fertility.

Female empowerment also affects the prevalence and composition of childlessness. The effectiveness of promoting gender equality in lowering fertility rates is generally amplified, in particular when opportunity-driven childlessness is high. On average, closing the gender wage gap increases total childlessness, due to an increase in opportunity-driven childlessness. For the poorest countries, however, which are more concerned with the type of childlessness that is driven by poverty, the effect goes in the other direction: closing the gender wage gap decreases total childlessness, due to its positive income effect. In these countries, the overall effect on fertility is then weakened when the specificities of the extensive margin of fertility are accounted for.

The rest of the paper is organized as follows. Section 2 describes the data and shows some relevant facts on childlessness in developing countries. The theoretical model is described in Section 3. Section 4 displays the identification strategy for the 
parameters of the model. In Section 5, we provide the results on the decomposition of childlessness and on the effect of education, mortality, family planning, and gender parity on childlessness and fertility. Section 6 concludes.

\section{Data and Facts}

After describing data sources, this section provides facts motivating why it is important not to overlook childlessness in developing countries.

\subsection{Data}

We use two sources of data. To establish stylized facts about fertility, childlessness, and marriage, we use census data from developing countries as harmonized by IPUMS International. ${ }^{6}$ We also use these data to measure educational homogamy and child mortality. Information on unwanted births is not available in census data. Hence, we use Demographic and Health Surveys (DHS) to estimate the proportion of women who do not control their fertility by country and education level. DHS data also provide information on the number of children ever born and children who survived. We decide not to use this source of data for the empirical moments used to calibrate the model for several reasons: the age range of women is shorter in DHS data than in census data (it stops at 50 years old), the literature has reported errors on the declaration of births Schoumaker (2009), and the number of observations is rather limited. We therefore only use DHS data for unwanted birth estimates and census data for everything else.

From IPUMS International, we select the latest census from the countries listed in Table 1, for which the variables "years of schooling" and both "children ever born" and "children surviving" are available. ${ }^{7}$ As we are interested in completed fertility, we accordingly sample women aged $40-54 .{ }^{8}$ We choose this age range because women are at the end of their fertility-life cycle and are not too old, so that the sample does not suffer from selection due to mortality. For men, we first compute the distribution of ages for the men married to our sampled women and drop the lowest and highest $5 \%$ of the distribution, in order to eliminate outliers. The sample of men are all men from the final age range (and varies across countries).

In the data, individuals can be married (legally or consensually), monogamously for most, single, divorced, separated, or widowed. Our theory focuses on two margins: marrying versus staying single, and having children versus remaining childless. We

6. These "data are especially valuable for studying trends and differentials in the core demographic processes and have become a major source for the reports of the U.N. Population Division" Ruggles et al. (2015).

7. More details about data selection are provided in Appendix A.1.

8. In Jamaica, Mali, and Vietnam, women over 49 are not asked the question relative to childbirth. In South Africa, women over 50 are not asked the question. Hence, we respectively limit the sample to 40-49 and $40-50$ in these countries. 
TABLE 1 . Continent and country codes, country names, census year, percentage of married women (\% M.W.), completed fertility of married and single mothers, and childlessness rates among married and single women.

\begin{tabular}{|c|c|c|c|c|c|c|c|c|}
\hline & Country & Country & Census & $\%$ & Mothers & ertility & Childl & ness \\
\hline & code & name & year & M.W. & Married & Single & Married & Single \\
\hline A & ARG & Argentina & 1991 & 0.90 & 3.18 & 2.30 & 0.07 & 0.74 \\
\hline $\mathrm{m}$ & BOL & Bolivia & 2001 & 0.88 & 4.70 & 3.00 & 0.03 & 0.30 \\
\hline $\mathrm{e}$ & BRA & Brazil & 2000 & 0.91 & 3.49 & 1.70 & 0.05 & 0.78 \\
\hline$r$ & $\mathrm{CHL}$ & Chile & 2002 & 0.82 & 2.96 & 2.00 & 0.03 & 0.37 \\
\hline $\mathrm{i}$ & $\mathrm{COL}$ & Colombia & 2005 & 0.78 & 3.34 & 2.40 & 0.06 & 0.39 \\
\hline $\mathrm{c}$ & CRI & Costa-Rica & 2000 & 0.84 & 3.75 & 2.91 & 0.03 & 0.33 \\
\hline $\mathrm{a}$ & DOM & Dom. Rep. & 2010 & 0.95 & 3.39 & 2.66 & 0.04 & 0.57 \\
\hline & ECU & Ecuador & 2010 & 0.85 & 3.68 & 2.49 & 0.05 & 0.42 \\
\hline & HTI & Haiti & 2003 & 0.92 & 4.77 & 3.38 & 0.07 & 0.44 \\
\hline & JAM & Jamaica & 2001 & 0.61 & 3.78 & 3.39 & 0.05 & 0.14 \\
\hline & MEX & Mexico & 2010 & 0.88 & 3.51 & 2.17 & 0.03 & 0.53 \\
\hline & NIC & Nicaragua & 2005 & 0.87 & 5.02 & 3.61 & 0.02 & 0.28 \\
\hline & PAN & Panama & 2010 & 0.87 & 3.44 & 2.53 & 0.04 & 0.48 \\
\hline & PER & Peru & 2007 & 0.90 & 3.87 & 1.82 & 0.03 & 0.36 \\
\hline & SAL & Salvador & 2007 & 0.77 & 3.84 & 2.80 & 0.04 & 0.26 \\
\hline & URY & Uruguay & 1996 & 0.90 & 2.90 & 2.31 & 0.06 & 0.67 \\
\hline & VEN & Venezuela & 2001 & 0.82 & 3.93 & 3.32 & 0.03 & 0.33 \\
\hline A & CAM & Cameroon & 2005 & 0.82 & 4.98 & 3.90 & 0.17 & 0.22 \\
\hline $\mathrm{f}$ & GHA & Ghana & 2010 & 0.96 & 4.71 & 3.00 & 0.08 & 0.46 \\
\hline $\mathrm{r}$ & KEN & Kenya & 1999 & 0.92 & 6.27 & 4.13 & 0.03 & 0.21 \\
\hline i & LBR & Liberia & 2008 & 0.86 & 5.27 & 4.18 & 0.11 & 0.26 \\
\hline $\mathrm{c}$ & MAR & Morrocco & 2004 & 0.91 & 4.86 & & 0.06 & \\
\hline $\mathrm{a}$ & MLI & Mali & 2009 & 0.93 & 5.08 & 3.67 & 0.14 & 0.48 \\
\hline & MWI & Malawi & 2008 & 0.98 & 5.30 & 4.24 & 0.05 & 0.39 \\
\hline & RWA & Rwanda & 2002 & 0.94 & 5.63 & 3.45 & 0.02 & 0.31 \\
\hline & SEN & Senegal & 2002 & 0.92 & 5.34 & 3.68 & 0.04 & 0.38 \\
\hline & SLE & Sierra Leone & 2004 & 0.89 & 4.62 & 4.14 & 0.09 & 0.47 \\
\hline & $\mathrm{TZA}$ & Tanzania & 2002 & 0.94 & 6.07 & 4.26 & 0.04 & 0.20 \\
\hline & UGA & Uganda & 2002 & 0.94 & 6.30 & 4.78 & 0.05 & 0.25 \\
\hline & ZAF & South Africa & 2001 & 0.75 & 3.61 & 2.81 & 0.05 & 0.17 \\
\hline & $\mathrm{ZMB}$ & Zambia & 2010 & 0.96 & 5.64 & 3.13 & 0.09 & 0.52 \\
\hline A & IDN & Indonesia & 1995 & 0.98 & 4.09 & & 0.04 & \\
\hline $\mathrm{s}$ & KHM & Cambodia & 2008 & 0.94 & 4.38 & 3.01 & 0.03 & 0.92 \\
\hline i & THA & Thailand & 2000 & 0.92 & 2.64 & & 0.06 & \\
\hline $\mathrm{a}$ & VNM & Vietnam & 2009 & 0.94 & 2.69 & 1.29 & 0.02 & 0.89 \\
\hline & WBG & Palestine & 1997 & 0.91 & 7.39 & & 0.04 & \\
\hline
\end{tabular}

Notes: Averages are weighted. For Morocco, Indonesia, Thailand, and Palestine, the Census only provides information on completed fertility for married women.

abstract from additional margins, such as staying married versus divorcing, having more than one wife versus being monogamous, and remarrying after widowhood versus staying single once widowed. We therefore adjust the sample to reflect the concepts of the model. We accordingly remove polygynous, divorced, separated, and widowed 
men and women from the sample. Polygynous couples face a different problem than monogamous ones, whereas divorced and widowed women experienced a change in family status during their reproductive lifetime, which likely affected their fertility decisions. ${ }^{9}$ By not accounting for these categories, we neglect the possible interactions between all these different marital statuses. ${ }^{10}$ Cohabitation is very common in the English-speaking Caribbean. ${ }^{11}$ We thus treat single women who are in a consensual union as if they were married.

In each country, we divide the population into 19 education categories at most, each category corresponding to the number of years of schooling. The variable "years of schooling" goes from none or preschool to 18 years or more. Table 2 shows the distribution and the average for the years of schooling by country for women. For some countries, the number of years of schooling has a maximum value of 12 or 13 years, which leads to underestimating the actual years of schooling for those who have a postsecondary education. This is true for Cambodia, Kenya, Peru, Sierra Leone, South Africa, Tanzania, and Uganda. For these countries, the years of schooling are adjusted using the information provided by the international recode variable of educational attainment. Appendix A.1 carefully explains how we made these changes. Table A.1 of this Appendix provides the total number of men and women in the sample.

\subsection{Childlessness in Developing Countries}

Using the selected sample from IPUMS International, we compute childlessness rates and the number of children ever born to mothers. Both variables are constructed from the children surviving variable to account for child mortality. Table 1 highlights strong intercountry differences in both the fertility of mothers and childlessness rates. High fertility rates can be found in Cameroon, Kenya, Tanzania, or Palestine, whereas the levels are much lower in Argentina, Brazil, Vietnam, or Chile, whatever the marital status of mothers. The same kind of variability applies to childlessness rates. Regarding the childlessness of married women, some countries like Cameroon, Liberia, and Mali have high childlessness rates, together with high fertility rates of married mothers. This indicates that countries where fertility is high can also have the highest childlessness rates.

First, we compare the relationships between the average completed fertility of mothers and average education, and average childlessness rates and average education across countries. The left panels of Figures 1 and 2 show that the fertility of mothers decreases as education increases, for both married and single women (with $R^{2}$ of $39 \%$

9. Appendix A.1 discusses marriage regimes and the likelihood of being in multifamily households for some particular countries where specific marital statuses that we do not consider might be relevant.

10. de la Croix and Mariani (2015) show how the intensity of polygyny depends on within and across gender inequality in a given society. Any policy is expected to affect marriage rates through this margin.

11. In Jamaica, many women who are coded as singles are in fact in a consensual union (only those who are formally married are coded as married). Roberts (1957) reports that $11 \%$ of women and $22 \%$ of men aged 45-54 are in common-law marriages in Jamaica. 
TABLE 2. Distribution and average of years of schooling by country-female.

\begin{tabular}{|c|c|c|c|c|c|c|c|}
\hline \multirow[t]{2}{*}{ Region } & \multicolumn{2}{|c|}{ Country } & \multicolumn{4}{|c|}{ Years of schooling } & \multirow[b]{2}{*}{ Average } \\
\hline & & & $\overline{0-4}$ & $5-8$ & $9-12$ & $\overline{13+}$ & \\
\hline \multirow[t]{17}{*}{ America } & ARG & Argentina & 0.21 & 0.44 & 0.23 & 0.12 & 7.83 \\
\hline & BOL & Bolivia & 0.56 & 0.17 & 0.15 & 0.13 & 5.46 \\
\hline & BRA & Brazil & 0.54 & 0.19 & 0.17 & 0.10 & 5.97 \\
\hline & CHL & Chile & 0.14 & 0.27 & 0.37 & 0.21 & 9.40 \\
\hline & COL & Colombia & 0.30 & 0.32 & 0.22 & 0.16 & 7.30 \\
\hline & CRI & Costa-Rica & 0.22 & 0.42 & 0.20 & 0.16 & 7.54 \\
\hline & DOM & Dominican Rep. & 0.30 & 0.24 & 0.27 & 0.19 & 8.05 \\
\hline & ECU & Ecuador & 0.19 & 0.31 & 0.27 & 0.23 & 8.90 \\
\hline & HTI & Haiti & 0.84 & 0.10 & 0.05 & 0.02 & 1.59 \\
\hline & JAM & Jamaica & 0.01 & 0.26 & 0.35 & 0.38 & 11.34 \\
\hline & MEX & Mexico & 0.23 & 0.27 & 0.34 & 0.17 & 8.16 \\
\hline & NIC & Nicaragua & 0.51 & 0.23 & 0.17 & 0.10 & 5.31 \\
\hline & PAN & Panama & 0.12 & 0.28 & 0.33 & 0.27 & 10.03 \\
\hline & PER & Peru & 0.28 & 0.18 & 0.41 & 0.12 & 7.96 \\
\hline & SAL & Salvador & 0.50 & 0.19 & 0.20 & 0.10 & 5.59 \\
\hline & URY & Uruguay & 0.12 & 0.45 & 0.27 & 0.15 & 8.16 \\
\hline & VEN & Venezuela & 0.22 & 0.34 & 0.43 & 0.01 & 7.39 \\
\hline \multirow[t]{14}{*}{ Africa } & CAM & Cameroon & 0.40 & 0.41 & 0.13 & 0.06 & 5.14 \\
\hline & GHA & Ghana & 0.50 & 0.09 & 0.30 & 0.11 & 5.44 \\
\hline & KEN & Kenya & 0.59 & 0.27 & 0.12 & 0.02 & 3.83 \\
\hline & LBR & Liberia & 0.77 & 0.08 & 0.12 & 0.03 & 2.42 \\
\hline & MAR & Morrocco & 0.78 & 0.10 & 0.09 & 0.04 & 2.15 \\
\hline & MLI & Mali & 0.89 & 0.07 & 0.02 & 0.02 & 1.08 \\
\hline & MWI & Malawi & 0.66 & 0.27 & 0.06 & 0.01 & 3.15 \\
\hline & RWA & Rwanda & 0.79 & 0.17 & 0.04 & 0.00 & 1.99 \\
\hline & SEN & Senegal & 0.77 & 0.12 & 0.07 & 0.04 & 2.18 \\
\hline & SLE & Sierra Leone & 0.81 & 0.10 & 0.07 & 0.03 & 1.79 \\
\hline & TZA & Tanzania & 0.70 & 0.26 & 0.03 & 0.01 & 2.82 \\
\hline & UGA & Uganda & 0.70 & 0.21 & 0.05 & 0.04 & 2.96 \\
\hline & ZAF & South Africa & 0.33 & 0.28 & 0.36 & 0.03 & 6.65 \\
\hline & $\mathrm{ZMB}$ & Zambia & 0.40 & 0.37 & 0.15 & 0.08 & 5.53 \\
\hline \multirow[t]{5}{*}{ Asia } & IDN & Indonesia & 0.46 & 0.35 & 0.16 & 0.02 & 4.82 \\
\hline & KHM & Cambodia & 0.70 & 0.20 & 0.09 & 0.00 & 3.27 \\
\hline & THA & Thailand & 0.81 & 0.07 & 0.08 & 0.04 & 4.83 \\
\hline & VNM & Vietnam & 0.16 & 0.31 & 0.47 & 0.06 & 8.00 \\
\hline & WBG & Palestine & 0.40 & 0.25 & 0.26 & 0.09 & 6.12 \\
\hline
\end{tabular}

and $47 \%$, respectively). For childlessness (right panels of Figures 1 and 2), there is no clear relationship ( $R^{2}$ of $11 \%$ and $1 \%$ ), which we believe is due to the different reasons for childlessness within these countries.

An important feature of the extensive and intensive margins of fertility is that they do not display a similar pattern with respect to the education of women. Figure 3 shows the average fertility of mothers and childlessness rates with respect to education, averaging over all women in the sample. Childlessness first decreases and then increases 

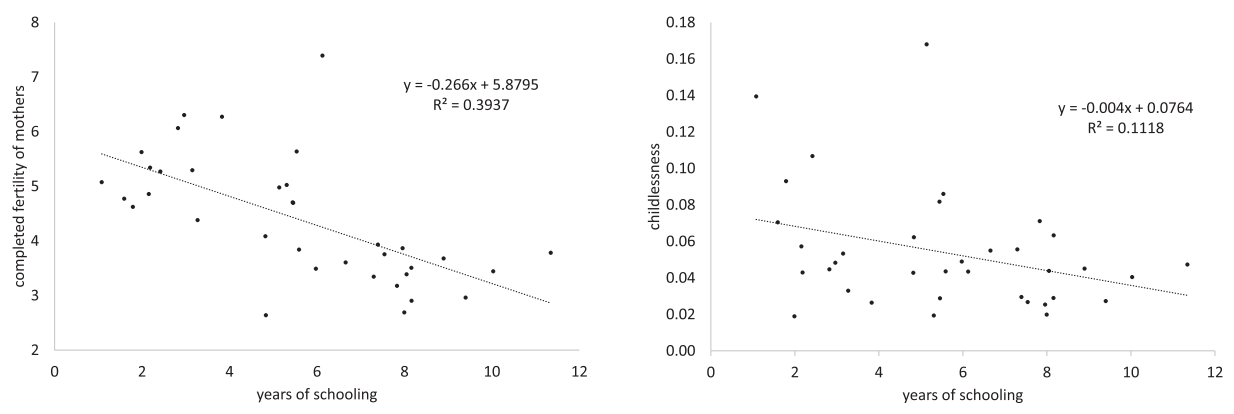

FIGURE 1. Completed fertility of mothers and education (left), and childlessness rates and education (right), averages by country for married women.
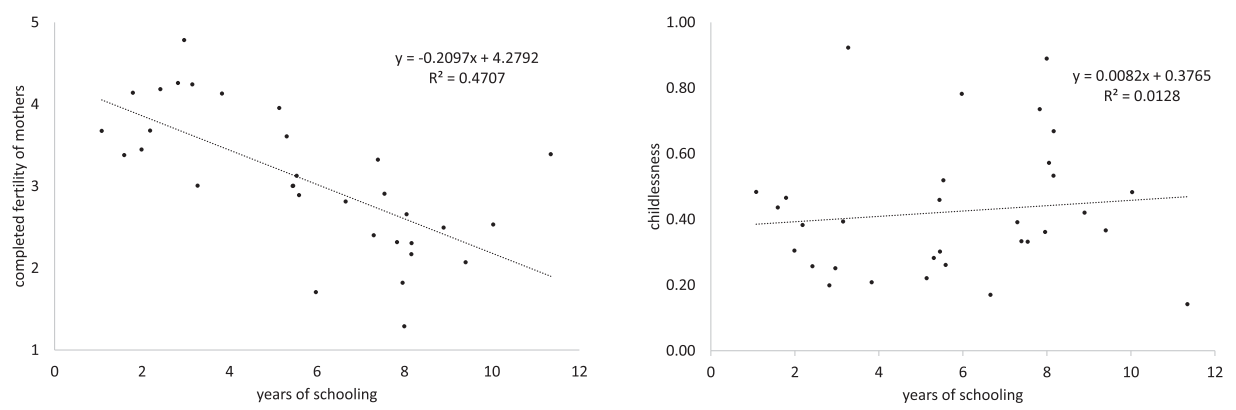

FIGURE 2. Completed fertility of mothers and education (left), and childlessness rates and education (right), averages by country for single women.

with education, for both single and married women. On average, childlessness attains a minimum at 9 years of schooling for married women and at 7 years of schooling for single women. ${ }^{12}$ On the contrary, the fertility of mothers decreases monotonically with education. On average, fertility decreases by 0.13 children for an additional year of mothers' education among married women and by 0.11 among single women. This shows that there is something crucial to understand by distinguishing between the two margins of fertility.

Considering the $\mathrm{U}$-shaped relationship between education and childlessness shown in Figure 3, we now assess how much of it is driven by cross-country variation. For example, it could be that the U-shape relationship arises because low-educated women are concentrated in Sub-Saharan Africa where childlessness is high, whereas highly

12. This feature does not rely on aggregation across countries. The U-shaped pattern of fertility with respect to female education for married women is present for 19 of the 36 countries considered. For single women, the U-shape appears in 19 out of 32 countries (data on the fertility of single women is not available everywhere). 

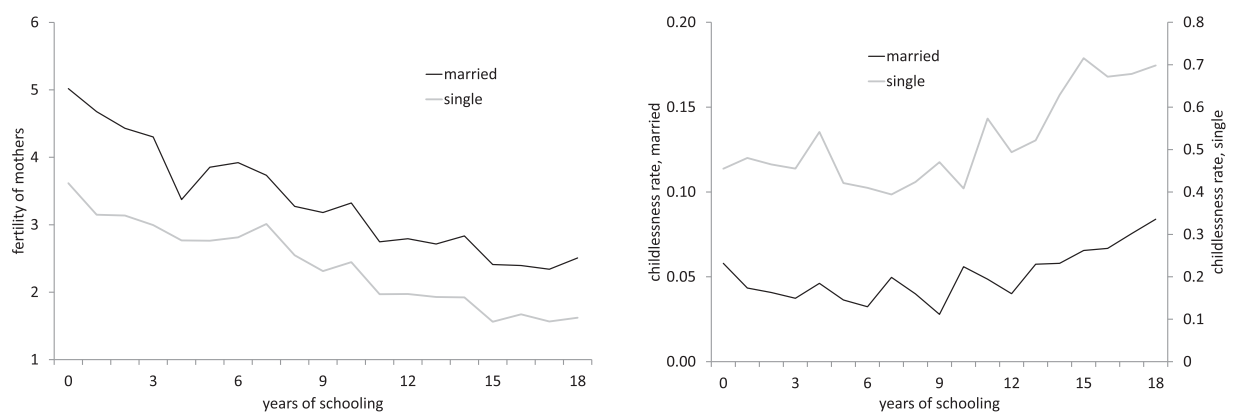

FIGURE 3. Completed fertility of mothers and childlessness, by years of education.

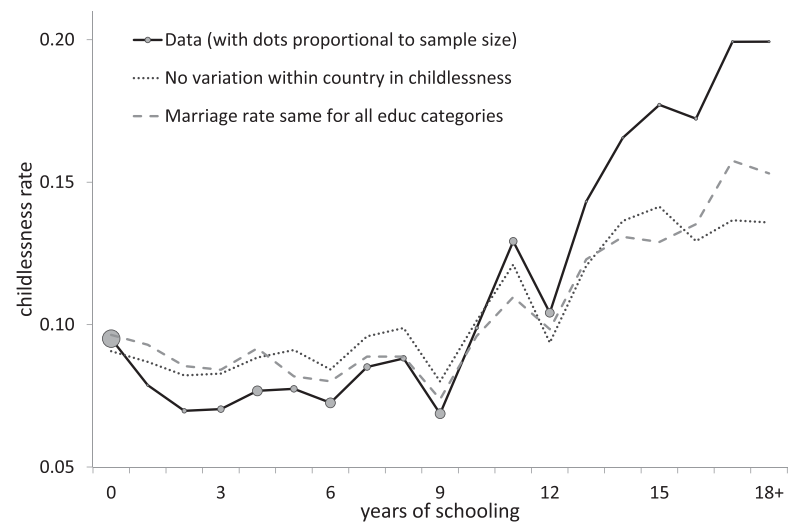

FIGURE 4. Global childlessness rates by years of schooling.

educated women are concentrated in middle-income countries such as Argentina. In Figure 4 , we compare the global childlessness rate $C^{e}$ by number of years of schooling $e$ in the data (solid line) to the global childlessness rate computed as if there was no variation in childlessness within countries (dotted line), $\overline{\mathrm{C}}^{e}$. Let us explain how these measures are constructed. The global childlessness rate for women with $e$ years of education is computed as

$$
\mathrm{C}^{e} \equiv \sum_{j} \omega_{j}^{e}\left[\mathrm{~m}^{e j} \mathrm{C}_{\text {married }}^{e j}+\left(1-\mathrm{m}^{e j}\right) \mathrm{C}_{\text {single }}^{e j}\right]
$$

where $\mathrm{m}^{e j}$ is the marriage rate of women with $e$ number of years of schooling in country $j, \mathrm{C}_{\text {married }}^{e j}$ is the childlessness rate of married women in country $j$ with $e$ years of education, $\mathrm{C}_{\text {single }}^{e j}$ is the childlessness rate of single women in country $j$ with $e$ years of education, and $\omega_{j}^{e}$ is the weight of country $j$ within the population of persons having $e$ years of schooling. The sample on which the sum is computed includes all 32 countries for which data on singles' fertility is available. The global childlessness 
rate without within-country variation, $\overline{\mathrm{C}}^{e}$, is computed as

$$
\overline{\mathrm{C}}^{e} \equiv \sum_{j} \omega_{j}^{e}\left[\mathrm{~m}^{e j} \sum_{e} \psi_{e}^{j} \mathrm{C}_{\text {married }}^{e j}+\left(1-\mathrm{m}^{e j}\right) \sum_{e} \vartheta_{e}^{j} \mathrm{C}_{\text {single }}^{e j}\right],
$$

where $\psi_{e}^{j}$ (resp. $\vartheta_{e}^{j}$ ) denote the share of persons having $e$ years of schooling among married (resp. single) women in country $j$. Comparing $\mathrm{C}^{e}$ and $\overline{\mathrm{C}}^{e}$ in Figure 4 , we observe that for low education levels, the dotted line is almost flat with respect to education categories. For higher education levels, it is increasing with education, but much less than in the data. This confirms that neglecting within-country variations and relying on between-country variations alone does not allow to generate the global U-shape.

A similar decomposition can be used to underline the importance of marriage rates to understand childlessness (as stressed in the Introduction). In Figure 4, we show a third pattern, which represents global childlessness rates (dashed line) as if there was no within-country variation in marriage rates. Such childlessness rate, denoted $\hat{\mathrm{C}}^{e}$, is computed by assuming that all education categories have the same marriage rate:

$$
\widehat{\mathrm{C}}^{e} \equiv \sum_{j} \omega_{j}^{e}\left[\mathrm{C}_{\text {married }}^{e j} \sum_{e} \psi_{e}^{j} \mathrm{~m}^{e j}+\mathrm{C}_{\text {single }}^{e j}\left(1-\sum_{e} \psi_{e}^{j} \mathrm{~m}^{e j}\right)\right] .
$$

Here too the U-shaped pattern is less marked. In particular, assuming constant marriage rates would lead us to underestimate childlessness rates for highly educated women. It is partly because they are more often single than the average woman that they have higher childlessness rates.

In the context of developing countries, the nonlinear relationship between childlessness and development has been documented by Poston and Trent (1982) in a slightly different way. They document a U-shaped relationship between childlessness and the development level of countries: childlessness in developing countries is high because a high proportion of women are affected by factors leading to subfecundity and consequently remain childless, whereas in developed countries, women face a higher opportunity cost in terms of foregone income when they raise their children and therefore decrease their fertility or even stay childless. As a country develops, childlessness decreases down to a minimum level and then increases because of the higher opportunity cost of having children. Using the average level of education as a proxy for development, our facts confirm those of Poston and Trent (1982).

Both margins of fertility can therefore adjust differently to development and this is important when computing the effect of a social program such as universal education, for instance. For countries that are mostly affected by the poverty-driven type of childlessness, such a program might increase fertility rather than have the expected negative effect from the intensive margin. 


\section{Theory}

This section exposes our theory of endogenous childlessness rates. This will then be used to quantify the channels through which different development trends affect total fertility when taking into account the specificities of the extensive margin. To keep notation light, we abstract from country specific indexes. All variables and parameters are country specific, but we consider one country at a time.

\subsection{Setup}

We consider an economy populated by heterogeneous adults, each being characterized by a triplet: sex $i=\{m, f\}$, education $e$, and nonlabor income $a$. Marriage is a two-stage game. In the first stage, agents are matched with an agent of the opposite sex from their own country. They decide to marry or to remain single. A match will end up in a marriage only if the two agents choose to marry. In the second stage of the game, they discover, at no cost, whether they are sterile (with probability $\chi_{i}$ ) or fecund (with probability $1-\chi_{i}$ ), and, for couples, whether they are able to control fertility (with probability $\kappa$ ) or not (with probability $1-\kappa$ ) or not. We consider that single women have full control over their fertility. ${ }^{13}$ Next, agents decide how much to consume and, eventually, how many children to give birth to, if any.

Preferences are identical across education levels and genders. The utility of an individual of gender $i$ is

$$
u\left(c_{i}, n\right)=\ln \left(c_{i}\right)+\ln (n+v),
$$

where $c_{i}$ is the individual's consumption, $n$ the number of children who survive to adulthood, and $v>0$ a preference parameter.

We assume that each newborn has a country-specific probability $q\left(e_{f}\right)$ of surviving to adulthood, which depends on the education of his/her mother. This probability is independent from the number of children born and from the marital status of the mother. The more educated a mother is, the smaller the probability for a newborn of dying: $q^{\prime}\left(e_{f}\right)>0 .{ }^{14}$ As in Sah (1991), the number of surviving children $n$ follows a binomial distribution such that the probability that $n$ children survive out of $N$ births is written:

$$
P(n \mid N)=\left(\begin{array}{l}
N \\
n
\end{array}\right)\left[q\left(e_{f}\right)\right]^{n}\left[1-q\left(e_{f}\right)\right]^{N-n} .
$$

13. Cleland et al. (2006) show that among 18 Sub-Saharan countries, the median percent of single women reporting no sexual intercourse was about $60 \%$ and that single women were more likely to use any method of contraception than married women.

14. The survival rates of children might also depend on the father's education. We can study this relationship in our sample from census data for married women. A linear probability model shows that the mother's education $e_{f}$ is twice as important as the father's education $e_{m}$ in determining survival. It also shows some substitutability between parents' education levels, as the effect of an interaction term $e_{f} \times e_{m}$ is negative for most countries. 
Both $N$ and $n$ are integers. This way of modeling mortality allows us to introduce uncertainty regarding a household's number of children. An alternative to this method is the one used in Leukhina and Bar (2010) in which households choose the number of surviving children. However, their framework cannot explain the share of women that remain childless due to mortality. One feature of binomial distributions is that events are independent, meaning that the survival of a child is independent from the survival of his/her siblings. Facing this type of uncertainty, parents will either have a precautionary demand for children (overshooting of fertility) or restrain their fertility to limit the potential number of child deaths (undershooting). ${ }^{15}$

To model couples' decision making, we assume a collective decision model following Chiappori (1988). Spouses negotiate on $c_{m}, c_{f}$, and $n$. Their objective function is

$$
W\left(c_{f}, c_{m}, n\right)=\theta u\left(c_{f}, n\right)+(1-\theta) u\left(c_{m}, n\right),
$$

where $\theta$ is the wife's bargaining power. Following de la Croix and Vander Donckt (2010), $\theta$ depends on relative earning power and is given by

$$
\theta \equiv \frac{1}{2} \underline{\theta}+(1-\underline{\theta}) \frac{w_{f}}{w_{f}+w_{m}} .
$$

We specifically assume that the negotiation power of spouses is bounded, with a lower bound equal to $\underline{\theta} / 2$, and positively related to their relative wage. The boundedness of the bargaining power function comes from the legal aspect of marriage: spouses have to respect a minimal level of solidarity within marriage. $w_{i}$ denotes the wage of a person $i$ that increases with education. Wages are exogenous and computed as follows:

$$
w_{f}=\gamma \exp \left\{\rho e_{f}\right\}, \quad w_{m}=\exp \left\{\rho e_{m}\right\},
$$

where $\rho$ is the Mincerian return of one additional year of education and $\gamma$ denotes the gender wage gap. Wages measure earning power, either from home production, agriculture, or as an employee. ${ }^{16}$

In the last stage of the game, once the marriage decision has been made, each person or couple maximizes their expected utility. In addition to the constraints imposed by their reproductive abilities, they will have to respect two additional constraints. First, beyond natural sterility, a woman has to consume at least $\hat{c}$ in order to be able to give birth:

$$
c_{f}<\hat{c} \Rightarrow N=0
$$

15. Following Baudin (2012), we can directly deduce from the individual utility function that parents will have a precautionary demand only if parameter $v$ is not too high. The exact condition to observe a precautionary demand of children is $v<q\left(e_{f}\right) N$.

16. Looking at the variable "Occupation, ISCO general" that records a person's primary occupation according to the major categories in the International Standard Classification of Occupations scheme for 1988, we find that a majority of Latin American women in our sample work as "service workers and shop and market sales". In Africa and Asia, a majority of women work as "agricultural and fishery workers". 
This assumption is discussed in Baudin et al. (2015) and accounts for the fact that lower-income groups are more often exposed to causes of subfecundity than the rest of the population, due to malnutrition, exposition to unhealthy environments, and risky behavior.

The second type of constraint is a budget constraint. We assume that each adult is endowed with a nonlabor income $a_{i}>0$ drawn from a log-normal distribution $\operatorname{Ln}-\mathcal{N}\left(m, \sigma^{2}\right)$ where $m$ is the mean of $\ln \left(a_{i}\right)$ and $\sigma^{2}$ its variance. The nonlabor income corresponds to the income that is uncorrelated with education. The total nonlabor income for a couple equals $a_{f}+a_{m}$. Each household has to pay a goods cost, $\mu$, which is a public good within the household. This type of cost is commonly assumed in the literature and gives some incentive to form couples (e.g., Greenwood et al. 2016).

We assume that single women can have children whereas single men cannot. The time endowment is 1 for married people and $1-\delta_{i}$ for singles. $\delta_{i}$ is the time cost that individuals lose due to their singleness. Single men's consumption $c_{m}$ equals income minus the household goods cost:

$$
c_{m}=\left(1-\delta_{m}\right) w_{m}+a_{m}-\mu .
$$

Single women can have children; their budget constraint is

$$
c_{f}+\phi n w_{f}=\left(1-\delta_{f}\right) w_{f}+a_{f}-\mu .
$$

Each fecund individual has to share time between child-rearing and working. Having children entails a time cost $\phi n .{ }^{17}$ If single, the mother has to bear the full time-cost alone. Given the time constraint $\phi n \leq 1-\delta_{f}$, the maximum number of children a single woman can have is

$$
\bar{N}_{S}=\left\lfloor\frac{1-\delta_{f}}{\phi}\right\rfloor \in \mathbb{N} .
$$

When married, the husband bears a share $1-\alpha$ of the child-rearing time. The total nonlabor income of a couple net of cost is $a=a_{m}+a_{f}-\mu$. Their budget constraint is

$$
c_{f}+c_{m}+\phi n\left(\alpha w_{f}+(1-\alpha) w_{m}\right)=w_{m}+w_{f}+a .
$$

The maximum fertility rate of a married woman equals

$$
\bar{N}_{M}=\left\lfloor\frac{1}{\alpha \phi}\right\rfloor \in \mathbb{N} .
$$

DEFINITION 1. $\mathcal{B}(n)$ denotes the remaining income of a couple having $n$ surviving children:

$$
\mathcal{B}(n)=(1-\alpha \phi n) w_{f}+(1-(1-\alpha) \phi n) w_{m}+a .
$$

17. We assume a child who does not survive does not cost parents anything. Relaxing this assumption neither changes our results, nor affects the estimates of childlessness rates in Section 4. 
We now solve the game backward, starting from the last step: the choice of fertility and consumption given the marital status.

\subsection{Behaviors in the Last Stage of the Game}

Although the fertility behaviors of single men, naturally sterile women, and couples who are unable to control their fertility are simple to analyze, the behaviors of fertile women or households are more complex. Since a woman cannot have children if she consumes less than $\hat{c}, N$ is potentially limited by income. A fecund single woman or a fecund couple can then be in one of three different cases: unconstrained fertility, poverty-driven childlessness, and limited fertility.

3.2.1. Single Men, Sterile Women, and Sterile Couples. As men cannot have children if single, they consume all their income minus the household goods cost. Their indirect utility then equals

$$
V_{m} \equiv u\left(\left(1-\delta_{m}\right) w_{m}+a_{m}-\mu, 0\right) .
$$

A single woman who is infertile has the same behavior as a single man and her indirect utility equals

$$
\tilde{V}_{f} \equiv u\left(\left(1-\delta_{f}\right) w_{f}+a_{f}-\mu, 0\right) .
$$

Finally a couple who cannot have children will share the household income such that $c_{f}=\theta \mathcal{B}(0)$ and $c_{m}=(1-\theta) \mathcal{B}(0)$. The indirect utilities of a man and a woman in a sterile marriage are respectively equal to

$$
\tilde{U}_{f} \equiv u(\theta \mathcal{B}(0), 0) \quad \text { and } \quad \tilde{U}_{m} \equiv u((1-\theta) \mathcal{B}(0), 0) .
$$

3.2.2. Fecund Single Women. The expected utility of a single woman who is not sterile and gives birth to $N$ children is written:

$$
\mathbb{E}_{n}\left[u\left(c_{f}, n\right) \mid N\right]=\sum_{n=0}^{N} P(n \mid N) u\left(c_{f}, n\right) .
$$

Unconstrained Fertility. This case arises when

$$
a_{f}-\mu+\left(1-\delta_{f}-\phi \bar{N}_{S}\right) w_{f} \geq \hat{c},
$$

which means that even if she has the maximal number of surviving births, she can consume at least $\hat{c}{ }^{18}$ In this case, she can give birth to $N \in\left[0, \bar{N}_{S}\right]$ and her optimal

18. Notice from (6) that when $a_{f}-\mu \geq \hat{c}$, working is not necessary to have the maximal number of children. 
fertility rate $N_{S}^{*}$ is such that

$$
\begin{aligned}
N_{S}^{*} & =\underset{N \in\left[0, \bar{N}_{S}\right]}{\operatorname{argmax}} \mathbb{E}_{n}\left[u\left(c_{f}, n\right) \mid N\right] \\
& =\underset{N \in\left[0, \bar{N}_{S}\right]}{\operatorname{argmax}} \sum_{n=0}^{N} P(n \mid N) u\left(w_{f}\left(1-\delta_{f}-\phi n\right)+a_{f}-\mu, n\right) .
\end{aligned}
$$

When $a_{f}-\mu+\left(1-\delta_{f}-\phi \bar{N}_{S}\right) w_{f}<\hat{c}$, the fertility rate of a single fecund woman is limited by her income. She may then either be in the poverty-driven childlessness or in the limited fertility case.

Poverty-Driven Childlessness. Sterility can arise when the woman is naturally sterile but also when $a_{f}-\mu+\left(1-\delta_{f}-\phi\right) w_{f}<\hat{c}$, meaning that she is too poor to have at least one surviving child while consuming at least $\hat{c}$. In such a situation: $N_{S}^{*}=0$ and $c_{f}=a_{f}-\mu+\left(1-\delta_{f}\right) w_{f}$.

Limited Fertility. When $a_{f}-\mu+\left(1-\delta_{f}-\phi\right) w_{f} \geq \hat{c}$, a single woman can have children but the number of children is limited by her income. Let us define $\breve{N}_{S}$ as the maximal number of surviving children a single woman can give birth to in the present case:

$$
\breve{N}_{S} \in \mathbb{N} \equiv\left\lfloor\frac{\left(1-\delta_{f}\right) w_{f}+a_{f}-\mu-\hat{c}}{\phi w_{f}}\right\rfloor .
$$

We can then determine her optimal fertility as

$$
\begin{aligned}
N_{S}^{*} & =\underset{N \in\left[0, \breve{N}_{S}\right]}{\operatorname{argmax}} \mathbb{E}_{n}\left[u\left(c_{f}, n\right) \mid N\right] \\
& =\underset{N \in\left[0, \breve{N}_{S}\right]}{\operatorname{argmax}} \sum_{n=0}^{N} P(n \mid N) u\left(w_{f}\left(1-\delta_{f}-\phi n\right)+a_{f}-\mu, n\right) .
\end{aligned}
$$

Notice that the three situations described previously cannot exist simultaneously. We can then denote the expected well-being of a fertile single woman as

$$
V_{f}=\mathbb{E}_{n}\left[u\left(w_{f}\left(1-\delta_{f}-\phi n\right)+a_{f}-\mu, n\right) \mid N_{S}^{*}\right] .
$$

3.2.3. Fecund Couples Controlling their Fertility. The expected weighted sum of utilities of a nonsterile couple equals:

$$
\mathbb{E}_{n}\left[W\left(c_{f}, c_{m}, n\right) \mid N\right]=\sum_{n=0}^{N} P(n \mid N) W\left(c_{f}, c_{m}, n\right) .
$$

As for single women, the fertility of couples is potentially limited by the income of spouses. 
Unconstrained Fertility. This case arises when the remaining income of the couple after having the maximal feasible number of children $\bar{N}_{M}$ remains greater than $\hat{c}$. This condition is written: $\mathcal{B}\left(\bar{N}_{M}\right) \geq \hat{c}$. In this case, the couple can choose their optimal number of births between zero and $\bar{N}_{M}$ such that

$$
\begin{aligned}
N_{M}^{*} & =\underset{N \in\left[0, \bar{N}_{M}\right]}{\operatorname{argmax}} \mathbb{E}_{n}\left[W\left(c_{f}, c_{m}, n\right) \mid N\right] \\
& =\underset{N \in\left[0, \bar{N}_{M}\right]}{\operatorname{argmax}} \sum_{n=0}^{N} P(n \mid N) W(\theta \mathcal{B}(n),(1-\theta) \mathcal{B}(n), n) .
\end{aligned}
$$

Let us now focus on poorer couples for whom $\mathcal{B}\left(\bar{N}_{M}\right)<\hat{c}$, so that reaching $\bar{N}_{M}$ is not feasible. In this situation, the income of the household will determine whether the couple is subject to poverty-driven childlessness or to a limitation in terms of the total number of births.

Poverty-Driven Childlessness. When

$$
\mathcal{B}(1)=(1-\alpha \phi) w_{f}+(1-(1-\alpha) \phi) w_{m}+a \leq \hat{c}
$$

then $N_{M}^{*}=0$ and spouses share their total income as a function of negotiation powers such that $\left\{c_{f}, c_{m}, n\right\}=\{\theta \mathcal{B}(0),(1-\theta) \mathcal{B}(0), 0\}$. This kind of sterility arises when the couple is so poor that if they had one surviving child, their income would then be smaller than $\hat{c}{ }^{19}$

Limited Fertility. When

$$
\mathcal{B}(1)=(1-\alpha \phi) w_{f}+(1-(1-\alpha) \phi) w_{m}+a_{f}+a_{m}-\mu>\hat{c},
$$

a couple can have children but their maximal number of children is smaller than $\bar{N}_{M}$ as it is limited by their income. We denote the maximal feasible number of births as $\breve{N}_{M}$; when $N=\breve{N}_{M}$, the wife's consumption is close to $\hat{c}$ and the husband's to zero:

$$
\breve{N}_{M}=\left\lfloor\frac{w_{f}+w_{m}+a-\hat{c}}{\phi\left(\alpha w_{f}+(1-\alpha) w_{m}\right)}\right\rfloor .
$$

The optimal behavior of a couple with limited fertility is then written:

$$
N_{M}^{*}=\underset{N \in\left[0, \breve{N}_{M}\right]}{\operatorname{argmax}} \sum_{n=0}^{N} P(n \mid N) W\left(c_{f}, c_{m}, n\right) .
$$

The $\left[0, \breve{N}_{M}\right]$ set can be rewritten $\left[0, \tilde{N}\left[\bigcup\left[\tilde{N}, \breve{N}_{M}\right]\right.\right.$ where

$$
\tilde{N} \equiv\left\lfloor\frac{w_{f}+w_{m}+a-\frac{\hat{c}}{\theta}}{\phi\left(\alpha w_{f}+(1-\alpha) w_{m}\right)}\right\rfloor .
$$

19. When $\mathcal{B}(1)=\hat{c}$, the woman can have one child but then her husband has zero consumption. 
As long as $n \leq \tilde{N}, \theta \mathcal{B}(n) \geq \hat{c}$, which means that the potential income of the household is high enough to raise the $n$ children without depriving spouses of consumption. Once $n$ becomes higher than $\tilde{N}$, the husband has to give his wife part of his consumption in order to enable her to consume $\hat{c}$. If such a behavior can be optimal up to a point, once the husband's consumption is too close to zero, the couple necessarily decides not to have children to prevent a situation of pauperized parenthood. This situation of childlessness is driven by poverty.

As in the case of single women, the situation that prevails for a fertile couple depends on spouses' income and only one of the previous cases prevails for a given set $\left\{w_{m}, w_{f}, a\right\}$. We then denote

$$
U^{f} \equiv \mathbb{E}_{n}\left[u\left(c_{f}(n), n\right) \mid N_{M}^{*}\right]
$$

the expected well-being of a woman in a fecund marriage, whereas

$$
U^{m} \equiv \mathbb{E}_{n}\left[u\left(c_{m}(n), n\right) \mid N_{M}^{*}\right]
$$

is the expected well-being of the husband.

3.2.4. Fecund Couples Who Do Not Control Fertility. With probability $1-\kappa$, a couple is unable to control their fertility. ${ }^{20}$ In this case, we assume that spouses have as many children as they can. Such a situation is relevant only if the total income of the family is sufficient to allow the woman to consume $\hat{c}$; couples with incomes such that $\mathcal{B}(1) \leq \hat{c}$ are not concerned by uncontrolled fertility (they are concerned by poverty-driven childlessness). For the others, their number of children, denoted $\widehat{N}$, equals:

$$
\widehat{N}= \begin{cases}\breve{N}_{M} & \text { if } \mathcal{B}\left(\bar{N}_{M}\right)<\frac{\hat{c}}{\theta} \\ \bar{N}_{M} & \text { otherwise. }\end{cases}
$$

Once maximal fertility has been reached, each spouse's consumption is

$$
\left\{c_{f}, c_{m}\right\}= \begin{cases}\left\{\hat{c}, w_{f}+w_{m}-\phi\left(\alpha w_{f}+(1-\alpha) w_{m}\right) \widehat{N}-\hat{c}\right\} & \text { if } \mathcal{B}\left(\bar{N}_{M}\right) \leq \frac{\hat{c}}{\theta} \\ \left\{\theta \mathcal{B}\left(\bar{N}_{M}\right),(1-\theta) \mathcal{B}\left(\bar{N}_{M}\right)\right\} & \text { otherwise }\end{cases}
$$

In the first case, the husband has to give his wife some of his consumption in order to allow her to have the maximal number of children. Such a situation is not optimal as the couple did not choose it. This will be important when a man evaluates the opportunity to marry the woman he has been matched with on the marriage market: if his potential bride has a high probability of not controlling her fertility, he has a high probability of becoming a poor father. This reduces his incentive to marry; this effect will be strong among poor men.

The wife's and the husband's expected well-being are denoted

$$
\widehat{U}^{f} \equiv \mathbb{E}_{n}\left[u\left(c_{f}(n), n\right) \mid \widehat{N}\right]
$$

20. See Bhattacharya and Chakraborty (2017) for a model with an explicit contraception technology. 


$$
\widehat{U}^{m} \equiv \mathbb{E}_{n}\left[u\left(c_{f}(n), n\right) \mid \widehat{N}\right]
$$

\subsection{First Stage: Marriage Decisions}

In the last stage of the game, agents know whether they are sterile or not, and whether they are able to freely determine their number of children. Nevertheless, they have to decide to marry or to remain single before obtaining this information and hence calculate the expected value of a marriage offer. We denote $\mathcal{M}_{f}\left(e_{f}, a_{f}, e_{m}, a_{m}\right)$ the value of accepting a marriage offer from a man endowed with $e_{m}$ and $a_{m}$ for a woman with an education $e_{f}$ and a nonlabor income $a_{f}$ :

$$
\begin{aligned}
\mathcal{M}_{f}\left(e_{f}, a_{f}, e_{m}, a_{m}\right)= & \left(\chi_{f}+\left(1-\chi_{f}\right) \chi_{m}\right) \tilde{U}^{f} \\
& +\left(1-\chi_{f}-\left(1-\chi_{f}\right) \chi_{m}\right)\left(\kappa\left(e_{f}\right) U^{f}+\left(1-\kappa\left(e_{f}\right)\right) \widehat{U}^{f}\right),
\end{aligned}
$$

where $\chi_{f}$ and $\chi_{m}$ respectively describe the percentage of females and males who are naturally sterile. For a man with an education $e_{m}$ and a nonlabor income $a_{m}$, the value of a marriage offer coming from a woman endowed with $\left\{e_{f}, a_{f}\right\}$ is

$$
\begin{aligned}
\mathcal{M}_{m}\left(e_{m}, a_{m}, e_{f}, a_{f}\right)= & \left(\chi_{m}+\left(1-\chi_{m}\right) \chi_{f}\right) \tilde{U}^{m}+\left(1-\chi_{m}-\left(1-\chi_{m}\right) \chi_{f}\right) \\
& \times\left(\kappa\left(e_{f}\right) U^{m}+\left(1-\kappa\left(e_{f}\right)\right) \widehat{U}^{m}\right)+\varepsilon,
\end{aligned}
$$

where $\varepsilon \in \mathbb{R}$ is a scale parameter accounting for a potential gender-specific surplus in marriage. When $\varepsilon>0$, males enjoy marriage more than females, everything else being equal, whereas the reverse is true when $\varepsilon<0 . \mathcal{S}\left(e_{i}, a_{i}\right)$ denotes the expected value of being single with education $e_{i}$ and nonlabor income $a_{i}$. This is written respectively for a woman and a man:

$$
\begin{aligned}
\mathcal{S}\left(e_{f}, a_{f}\right) & =\chi_{f} \tilde{V}^{f}+\left(1-\chi_{f}\right) V^{f}, \\
\mathcal{S}\left(e_{m}, a_{m}\right) & =V^{m} .
\end{aligned}
$$

A match on the marriage market will end up married only if both partners are willing, that is to say if and only if

$$
\mathcal{M}_{f}\left(e_{f}, a_{f}, e_{m}, a_{m}\right) \geq \mathcal{S}\left(e_{f}, a_{f}\right) \quad \text { and } \mathcal{M}_{m}\left(e_{m}, a_{m}, e_{f}, a_{f}\right) \geq \mathcal{S}\left(e_{m}, a_{m}\right) .
$$

In Appendix D, we study the case in which only the consent of the groom is needed for a marriage to occur.

Some properties of the model will be crucial to fit the stylized facts presented in the previous section. The U-shaped pattern of childlessness in the data is related to the coexistence of the various types of childlessness and the way their intensity varies with education. Natural sterility is not at stake here as we have assumed it is uniformly 
distributed across the population. ${ }^{21}$ On the contrary, poverty-driven childlessness arises when income is not sufficient to allow the woman to consume at least $\hat{c}$. It therefore decreases with income and explains why total childlessness decreases with education at low levels of education. Finally, opportunity-driven childlessness arises when, despite being fertile and not facing a binding economic constraint on their decisions, single women or couples decide not to have children. Those who are concerned by this situation are women earning high salary incomes, who hence have a greater opportunity cost of raising children. Opportunity-driven childlessness is responsible for the increasing pattern of childlessness rates, at high levels of education. Notice that better-educated mothers also reduce their number of births (i.e., the intensive margin of fertility).

Concerning the pattern of marriage rates observed in the data, the following elements are important. First, the risks of sterility as well as of unwanted pregnancies can be powerful incentives to stay single. Sterility can be natural but also due to poverty. This implies that a poor man has a low incentive to marry a poor woman since the risk of being sterile due to poverty is great. Furthermore, marrying a woman with low education increases the risk of losing control over fertility when married. For a rich man, this only means having many children, whereas for a poor man, it means suffering consumption deprivation. This mechanism has a negative impact on the degree of assortativeness. On the other hand, the sharing rule within marriage affects the degree of assortativeness positively.

Child mortality is also crucial to marriage decisions. The risk of ending up with zero children due to mortality lowers men's willingness to marry since having children is the main advantage of marriage for a man. In this case, the single woman or the couple is neither naturally nor socially sterile. For any woman endowed with $e_{f}$ and giving birth to $N$ children, the probability of being childless due to mortality is $P(0 \mid N)=\left(1-q\left(e_{f}\right)\right)^{N}$. If the law of large numbers applies, the proportion of women who are childless because of child mortality in each category of education equals $\sum_{N=0}^{\bar{N}_{M}} \eta_{\left\{N, e_{f}\right\}}\left(1-q\left(e_{f}\right)\right)^{N}$, with $\eta_{\left\{N, e_{f}\right\}}$ describing the proportion of women with an education level equal to $e_{f}$ who have $N$ births. As the probability that a newborn survives is positively correlated to his/her mother's education, mortality-driven childlessness is not uniformly distributed across the population. It is not necessarily greater among low-educated women than among highly educated women. Indeed, low-educated women face a higher risk that each of their children will die but have a higher fertility rate when they are not sterile, whereas highly educated women face a lower risk but have fewer children.

Marriage decisions matter to understand how economic and demographic shocks may alter the fertility and childlessness rates of single and married women in an asymmetric way. For instance, let us assume that child mortality rates decrease significantly. For single women, the effect of such a shock on childlessness depends

21. If the law of large numbers applies, a share $\chi_{f}$ of single women will be sterile, whereas the share of sterile couples will be higher and equal to $\chi_{f}+\left(1-\chi_{f}\right) \chi_{m}$. The prevalence of natural sterility depends on education only indirectly through the marriage rate. 
heavily on the type of match in the marriage market. In the eyes of highly educated, rich men, this shock increases the attractiveness of low-educated women, as the risk to end up childless due to child mortality is reduced. Thus, everything else being equal, the reduction in child mortality rates should increase the marriage rate of low-educated women. This increase will however give rise to an important selection effect: women who will accept new marriage offers are those who rely more on marriage to escape extreme poverty (those with the lowest nonlabor income). Since the remaining single women are those who relied less on marriage to have children, childlessness rates may be lower after the mortality shock. Now, in the eyes of low-educated men, loweducated women become less attractive. Indeed, high child mortality rates operate as a Malthusian positive check on women not controlling their fertility, hence, limiting the final number of children as well as the risk of pauperization faced by poor men. As they have lost attractiveness, some low-educated women who should have married become poor single women, thus potentially childless. For married women, the impact of a positive mortality shock on childlessness is unambiguously negative as fewer families are decimated by child mortality.

\section{Identification of the Parameters}

Here, we estimate the parameters of the theory developed in Section 3 from the data in order to provide results on the decomposition of childlessness and the effect of development on fertility.

\subsection{A Priori Information}

Natural Sterility. Some parameters are fixed a priori. The two sterility parameters, $\chi_{f}$ and $\chi_{m}$, are fixed at $1 \%$. The percentage of naturally sterile couples, $\chi_{f}+\left(1-\chi_{f}\right) \chi_{m}$, is then equal to $1.9 \%$. This allows us to match the lowest childlessness rates in our sample (Nicaragua, Rwanda, and Vietnam). ${ }^{22}$

Wages. To compute wages, we need to know the parameters $\rho$, which is the Mincerian return of one additional year of education, and $\gamma$, which denotes the gender wage gap. $10 \%$ is a usual yardstick for the Mincerian return to years of schooling. Evidence for developing countries is however mixed. Old evidence shows that the rates of return to investment in education in developing countries are above this benchmark. Recent country-specific studies, however, find lower returns, closer to 5\% (see the survey

22. The ideal population to measure sterility among couples is one in which marriage is associated with the desire to have children, women marry young, do not divorce (e.g., because of sterility), are faithful to their husbands, and live in a healthy environment. The closest to this ideal are Hutterites. According to Tietze (1957), who studies sterility rates among this population, we should set the percentage of naturally sterile couples, $\chi_{f}+\left(1-\chi_{f}\right) \chi_{m}$, at $2.4 \%$. In our sample here, couples from Nicaragua, Rwanda, and Vietnam are even less childless than Hutterites. 
of Oyelere 2008 for Africa). As we impute this return starting from the first year of education, we have decided to be relatively conservative and set $\rho=0.05$. A robustness analysis to this assumption is provided in Appendix D where we use the values provided in Montenegro and Patrinos (2014) instead. Country-specific gender wage gaps $\gamma$ are computed from the Global Gender Gap Report (Hausmann et al. 2013) normalizing the measure to 1 for Iceland, the country with the smallest gap in the world. For a few countries (Haiti, Rwanda, Sierra Leone, and Palestine), data are not available, and the sample average (0.794) was imputed to them. All the resulting gender wage gaps are shown in Table A.4 of Appendix A.3. All wages are finally normalized so that the maximum wage (that of a man with 18 years of schooling) is equal to one for each country.

Survival Rates. We use IPUMS data to compute survival rates per education category in each country. For each woman in the data, we know how many children she gave birth to and how many of them survived. The ratio between the total number of surviving children and the total number of births gives a measure for the synthetic survival rate, which includes both child and young adult mortality. The relationship between mothers' education and survival rates is increasing in all countries.

Assortative Matching. There are many ways of measuring assortativeness in marriage (Greenwood et al. 2014). In Baudin et al. (2015) (in Appendix C.8), we introduce an exogenous way to generate the observed degree of assortativeness by assuming, as in Fernández-Villaverde et al. (2014), that a fraction of the female population draws a possible match from their education category, whereas the remaining women draw from the total population. This assumption is well suited when the number of education categories is not too large, and therefore puts several subcategories together. Here, instead, we assume that the meeting probabilities depend on the distance between the two people's education. More precisely, we assume that the percentage of meetings between women of education $e_{f}$ and men of education $e_{m}$ is given by

$$
m\left(e_{f}, e_{m}\right)=p\left(e_{f}\right) q\left(e_{m}\right) e^{-\lambda\left|e_{f}-e_{m}\right|} s^{f}\left(e_{f}\right) s^{m}\left(e_{m}\right),
$$

where $s^{f}\left(e_{f}\right)$ and $s^{m}\left(e_{m}\right)$ are respectively the shares in the population of women and men with $e_{f}$ and $e_{m}$ years of schooling. Parameter $\lambda$ is a measure of assortativeness. With $\lambda=0$, the matching is random and $m\left(e_{f}, e_{m}\right)=s^{f}\left(e_{f}\right) s^{m}\left(e_{m}\right)$. The $m\left(e_{f}, e_{m}\right)$ can be seen as elements of a $19 \times 19$ contingency table describing who matches whom as a function of education. The $p\left(e_{f}\right)$ and $q\left(e_{m}\right)$ are scale factors that allow the rows and the columns of the contingency table to sum up to $s^{m}\left(e_{m}\right)$ and $s^{f}\left(e_{f}\right)$, and depend on $\lambda$.

For each country, the calibrated measure of assortativeness, $\lambda$, is obtained by maximizing the Mantel $r$ statistics between the underlying contingency table of matches and the observed contingency table of marriages. The Mantel $r$ statistics 
is a measure of the correlation between the two matrices. This procedure will lead to a light overestimation of assortativeness. Indeed, maximizing the correlation between a match matrix and a marriage matrix leads to the right degree of assortativeness if accepting the match is random. The model however generates some degree of endogenous assortativeness, through the fact that the bargaining power depends on relative education levels, leading to too large a degree of assortativeness in the artificial economy. The degree of endogenous assortativeness is very small though, so this is not an important issue.

Appendix B.1 describes the procedure in more detail and provides the calibrated measures of assortativeness, $\lambda$, in each country. Appendix D shows the estimation of the parameters in the absence of assortativeness $(\lambda=0)$.

Unwanted Births. DHS data allows us to estimate the proportion of women who do not control their fertility. We denote a woman as not able to control fertility if she declares that her ideal fertility is at least two fewer children than her completed fertility and if she believes that her partner did not want more children than she did. This last requirement gives us confidence that the difference between the number of children ever born and the ideal number of children is not the outcome of a rational household decision in which, for instance, the husband has a higher ideal number of children, together with a higher bargaining position. We use this variable to predict the probability for a woman with $e_{f}$ years of schooling of not controlling her fertility in country $j$. Appendix A.2 discusses alternative measures of unwanted births and provides details on the sample construction.

The literature about desired fertility and family planning (see, for instance, Pritchett 1994a) reports the existence of an ex post rationalization bias, due to women declaring their ideal number of children in conformity with their actual number of children. Such a bias undoubtedly exists in our measure and could lead to underestimating the probability of experiencing an undesired birth. We discuss this issue in Appendix A.2 where we provide five alternative measures for uncontrolled fertility. In order to evaluate the importance of this potential bias, Appendix D provides a robustness check of the estimation and the results, when a woman is considered as not controlling her fertility if she believes that her partner did not want more children than she did (similarly to the benchmark definition), but she had at least one more child than her declared ideal fertility.

Notice finally that the number of countries for which DHS data on unwanted births is available is lower than the number of countries for which we have census data (25 out of 36 countries). The country codes of the countries for which both census and DHS data are available are in bold in Table A.1 of Appendix A.1. For the countries for which we did not have the DHS data, we had to make an assumption regarding the proportion of women who do not control their fertility. As detailed in Appendix A.2.2, the countries where there is no DHS data are given the probability of not controlling fertility from the country where the fertility rates with respect to education are the most similar, within the same continent. 


\subsection{Minimum Distance Estimates}

We next identify the remaining 11 parameters of the model using the simulated method of moments (SMM). The moments are the marriage rates of men and women, the completed fertility of mothers, and the childlessness rates among both single and married women, for the 19 education categories. ${ }^{23}$ As there is an equal number of men and women in the model, we adjust the marriage rate of men to equal the marriage rate of women in each economy. This sums to 114 moments per country. The objective function to minimize is given by

$$
f(p)=[d-s(p)][W][d-s(p)]^{\prime},
$$

where $p$ is the vector of the parameters of the model, $d$ denotes the vector of empirical moments and $s$ the vector of simulated moments, depending on the parameters. $W$ is a diagonal weighting matrix with $1 / d^{2}$ as elements, implying that we minimize the sum of squared deviation in percentage terms. The minimization is performed under the constraint of reproducing the aggregate marriage rate perfectly. We impose this constraint in order to compute the aggregate childlessness rates with the right weights of single and married people.

To compute the simulated moments, we consider a large number of women $(100,000)$ for each category of education. For each woman, we draw her nonlabor income from a log-normal distribution $\operatorname{Ln}-\mathcal{N}\left(m, \sigma^{2}\right)$. The nonlabor income $a_{i}$ has a mean denoted $\beta=\exp \left\{m+\sigma^{2} / 2\right\}$. The parameter $\sigma$ is the standard deviation of the underlying normal distribution of $\ln a_{i}$. For each woman in each category of education, we also draw a potential husband of a certain education category, with a probability given in equation (9). ${ }^{24}$ For each level of men's education, the nonlabor income is drawn from the same distribution as for women. Each woman, given her education and country, also faces survival probabilities for her children, and a probability of not controlling her fertility, as detailed in the previous section. Given these probabilities, we compute the expected utility when married and single, and the expected utility of the possible husband we have drawn for her. We thus obtain a decision about marriage for each person. Then, drawing realizations for mortality and fertility control shocks, we compute her actual fertility. For each category of education for women, we therefore obtain a large number of decisions about marriage and fertility that we can average, and calculate the simulated moments.

We estimate the parameters for each country separately. As nothing guarantees that the objective function to minimize, $f(p)$, is a well-behaved concave function of the parameters, we base the estimation on a global optimization method. We use the genetic algorithm developed by Charbonneau (1995), which allows global extrema to be found in highly nonlinear optimization problems where there exists a large number

23. Tables E.3- E.8 of the Online Appendix show the exact values of the empirical moments.

24. Appendix D studies the robustness of the results when we assume a random matching marriage market instead. 
of local extrema. This makes our estimation robust to the initial guess on the parameters we feed into the algorithm.

To further support the precision of our estimates, we also compute bootstrapped standard errors. First, we draw 100 random new samples with replacement from the original data for each country. Each resample is of equal size of the original one but the frequency of each observation changes. For each of these resamples we generate the 114 moments per country and estimate the corresponding parameters. In this estimation, we applied the global optimization method only once and then re-optimized for each bootstrapped sample moment with the local optimization algorithm. For each country, we compute the mean and the standard deviation of the parameters estimated from the 100 resamples. These means and standard deviations of the sampling distributions give us bootstrapped estimates of the mean and standard error of the sample statistics. The results are reported in Tables C.1-C.3 for all countries. We next aggregate over countries by averaging the parameters using the countries' specific weights. The third and fourth columns of Table 3 show the mean and standard errors of these averages. The last column of Table 3 shows the between country standard deviation. Figures C.1-C.3 show the empirical and simulated moments, using the estimated values of the parameters for each country, and then aggregating country-specific simulated moments.

Let us now interpret the average values of the parameters, their standard error, and their cross-country variation. The time cost for one child, $\phi$, the share of child-rearing supported by women, $\alpha$, and the time cost of being single for women, $\delta_{f}$, imply an upper bound on fertility of 7 children for married women and 5 for single women. The difference between the time costs of being single for men and women, $\delta_{m}$ and $\delta_{f}$, is noteworthy (and it is present in a large majority of countries): it implies that the gain from marriage in terms of time accrues mostly to men, who seem less efficient than women at managing their lives when single. The mean of the nonlabor income, $\beta$, the minimum consumption level to be able to procreate, $\hat{c}$, and the goods cost to be supported by a household, $\mu$, should be interpreted in light of the normalization for wages. Their values imply that a single woman with average nonlabor income $(0.537)$

TABLE 3. Identified parameters, average values.

\begin{tabular}{lcccc}
\hline Description & & Mean & $\begin{array}{c}\text { SE of the } \\
\text { mean }\end{array}$ & $\begin{array}{c}\text { between } \\
\text { country SD }\end{array}$ \\
\hline Time cost for one child & $\phi$ & 0.188 & 0.001 & 0.014 \\
Mean of the nonlabor income & $\beta$ & 0.406 & 0.005 & 0.173 \\
Preference parameter & $v$ & 9.367 & 0.067 & 1.055 \\
Min. consumption level to be able to procreate & $\hat{c}$ & 0.354 & 0.002 & 0.130 \\
Goods cost to be supported by a household & $\mu$ & 0.281 & 0.003 & 0.138 \\
Share childrearing supported by women & $\alpha$ & 0.783 & 0.004 & 0.126 \\
Time cost of being single (men) & $\delta_{m}$ & 0.197 & 0.002 & 0.116 \\
Time cost of being single (women) & $\delta_{f}$ & 0.077 & 0.002 & 0.097 \\
Bargaining parameter & $\underline{\theta}$ & 0.442 & 0.011 & 0.293 \\
Std. error of the natural log of nonlabor income & $\sigma^{2}$ & 0.420 & 0.005 & 0.143 \\
Scale parameter (male marriage surplus) & $\varepsilon$ & 0.128 & 0.003 & 0.055 \\
\hline
\end{tabular}



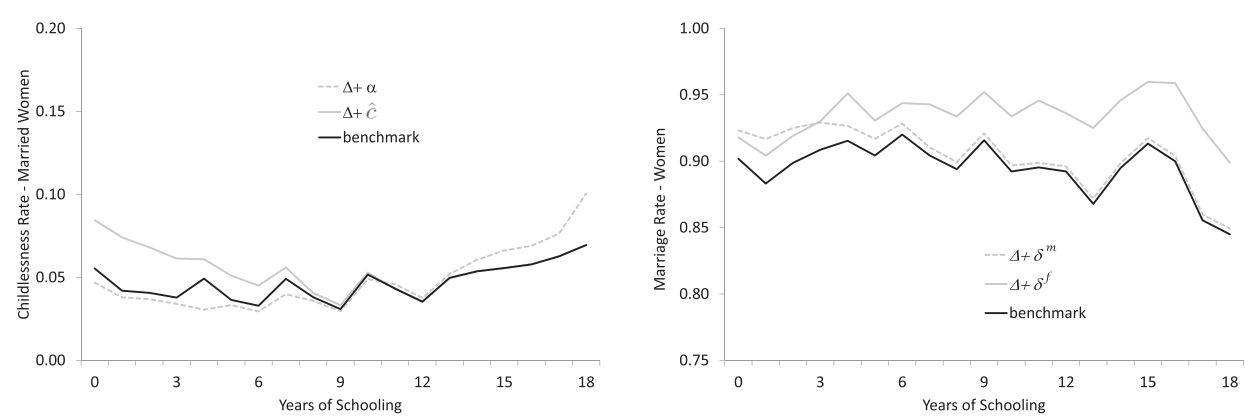

FIGURE 5. Left panel: identification of $\hat{c}$ (solid gray) and $\alpha$ (dashed gray). Right panel: identification of $\delta_{f}$ (solid gray) and $\delta_{m}$ (dashed gray).

and no education $\left(w_{f}=0.306\right)$ cannot have more than three children, whereas paying the cost $\mu$ and consuming $\hat{c}$, she then is in the "limited fertility case" of Section 3.2.2. Nevertheless, this does not prevent the noneducated single women from the poorest countries from being childless because of their poverty. Finally, $\varepsilon>0$ suggests that men have a higher surplus from marriage than women.

The estimated standard errors of the parameters are small. The reason is as follows. The moments used to estimate the parameters are computed from census data, and thus rely on a large sample of individuals. The moments computed from each resample in the bootstrap procedure are thus relatively close to each other. The small size of the standard errors suggest that small perturbations in the data lead to very similar estimated parameters and therefore that the model is well-identified.

Figure 5 sheds light on how some of the parameters of the model are identified from the data. The black lines of the left and right panels respectively show the relationship between the childlessness rates of married women and years of schooling, and the relationship between female marriage rates and years of schooling, aggregating the simulated moments across countries. The other lines show how the slopes of the relationships change when we change some of the parameters. For a change in each parameter, we keep all the others constant at their estimated values. This allows to infer from which empirical moments each parameter is identified. Online Appendix B.2 shows how each of the eleven parameters of the structural model is identified from the data.

The left panel of Figure 5 shows how the slope of the relationship between childlessness and education changes after we respectively set the share of child-rearing supported by women, $\alpha$, equal to one, in all countries, or we increase the minimum consumption level to be able to procreate, $\hat{c}$, by $23 \%$ on average. A higher $\hat{c}$ increases poverty-driven childlessness, but leaves opportunity-driven childlessness unchanged. A higher $\alpha$, on the contrary, mostly affects opportunity-driven childlessness. ${ }^{25} \mathrm{We}$ can

25. To be precise, Appendix B.2 shows that changing $\alpha$ and $\hat{c}$ also affects marriage decisions. A higher $\alpha$ gives a man an extra incentive to accept a marriage with a low-educated woman, as his opportunity cost in 


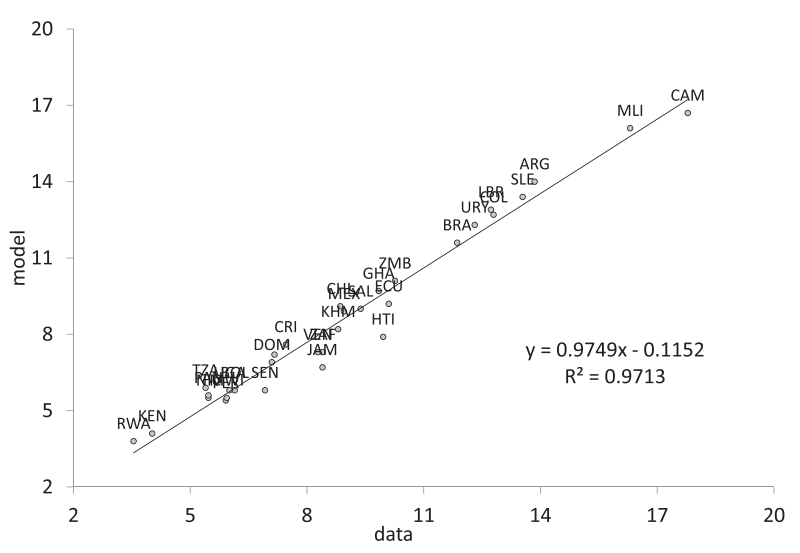

FIGURE 6. Theoretical versus empirical childlessness rates. Morocco, Indonesia, Thailand and Palestine are excluded as we do not have the information on the childlessness of singles for them.

then infer that $\hat{c}$ is identified from the decreasing part of the U-shaped relationship between childlessness and the education of married women, whereas $\alpha$ is identified from the increasing part of the U-shaped relationship.

The right panel of Figure 5 shows how the slope of the relationship between female marriage rates and education is affected when we respectively increase the time cost of being single for men, $\delta_{m}$, and for single women, $\delta_{f}$, by 0.1 on average, all else kept at the estimated values. A higher $\delta_{f}$ increases the incentives for highly educated women to marry because, for them, time is the most expensive. A higher $\delta_{m}$ makes men more willing to accept low-educated women in order to gain time. We can therefore conclude from this that $\delta_{f}$ is identified from the slope of the female marriage rates for highly educated women and $\delta_{f}$ is identified from the slope of the female marriage rates for low-educated women.

Figure 6 illustrates the fit of the structural model in terms of childlessness rates. We correlate the observed level of childlessness with the simulated one. The model explains $97 \%$ of the variation in childlessness across countries. In Appendix C.2.2, we compare the fit of our structural estimation to that of an ad-hoc linear regression model in order to appreciate the power of our quantitative approach. We show that the discipline imposed by our theoretical approach leads to a rather limited loss of fit, whereas it allows to both decompose childlessness into its four components and estimate the relationship between fertility, childlessness, and development.

The last column of Table 3 shows that, for some of the structural parameters, there is quite substantial between-country variations. Looking further in Appendix C.3 at the intercountry variability of our estimated parameters, we show it may be related to

terms of foregone income due to child-rearing diminishes. A higher $\hat{c}$ has the opposite effect: men are less willing to marry low-educated women, as they would have to provide too much in terms of consumption to their wives. 
deep-rooted factors in comparative economic development stressed by the literature. We show that the minimum consumption level required to be able to procreate, $\hat{c}$, relates negatively to the quality of institutions, proxied by the percentage of the population that was European or from European descent by 1900 from Acemoglu, Johnson, and Robinson (2002). The share of the child-rearing time supplied by women, $\alpha$, can be positively associated to matrilocal postmarital residence rules (from Alesina et al. 2013). How much intrahousehold bargaining depends on relative wages, which is accounted for by parameter $\underline{\theta}$, is also associated to patrilocal postmarital residence rules.

\section{Results}

We now decompose the estimated rates of childlessness into its four components and assess how social changes affect total fertility rates when accounting for the different causes of childlessness. As a reminder, opportunity-driven childlessness happens when a woman is able to have at least one child, but prefers not to have any. Formally, this happens when $\mathcal{B}(1)>\hat{c}$ and $N_{M}^{*}=0$ for married women and when $a_{f}-\mu+\left(1-\delta_{f}-\phi\right) w_{f}>\hat{c}$ and $N_{S}^{*}=0$ for single women. Poverty-driven childlessness arises when having one kid is not affordable, that is when $\mathcal{B}(1) \leq \hat{c}$ for couples and $a_{f}-\mu+\left(1-\delta_{f}-\phi\right) w_{f} \leq \hat{c}$ for single women. Finally, mortality driven childlessness occurs when a woman has a positive number of births, but none of these survives. Formally, this happens when $\mathcal{B}(1)>\hat{c}, N_{M}^{*}>0$ but $n=0$ for couples, and $a_{f}-\mu+\left(1-\delta_{f}-\phi\right) w_{f}>\hat{c}, N_{S}^{*}>0$ but $n=0$ for singles.

\subsection{Decomposition of Childlessness}

We show the decomposition of the sources of childlessness for the 36 developing countries considered in Table 4. We also show the decomposition when we aggregate all countries (line ALL) and when we aggregate all the countries for which we have both DHS and census data (line DHS). On average, we estimate that $3.5 \%$ of women are childless because the opportunity cost of child-rearing is too high. The remaining part of childlessness is due to poverty and natural reasons. $2.3 \%$ of women are childless because of poverty and $0.5 \%$ because all their children died. Argentina, Uruguay, Colombia, and Chile have the highest levels of opportunity-driven childlessness, respectively $11.0 \%, 9.7 \%, 7.4 \%$, and $7.0 \%$. Poverty-driven childlessness is the main reason of childlessness in Mali (12.6\%), Cameroon (11.8\%), Sierra Leone (8.5\%), and Liberia (6.9\%). Mortality-driven childlessness is not a major cause of childlessness. It however reaches the highest levels in Sierra Leone (1.9\%) and Ghana (1.7\%).

Figure 7 correlates the two main types of childlessness, poverty-driven childlessness and opportunity-driven childlessness, with the mean education level of each country. From the left panel, we see that a one-year rise in school-life expectancy reduces poverty-driven childlessness by 0.68 percentage points on average. There are four main outliers with unusually high levels of poverty-driven childlessness given 
Baudin, de la Croix, and Gobbi Childlessness and Development

TABLE 4. Decomposition of childlessness into its four components (\%), by country.

\begin{tabular}{|c|c|c|c|c|c|c|c|}
\hline \multicolumn{2}{|c|}{ Geographical details } & \multicolumn{4}{|c|}{ Types of childlessness } & \multicolumn{2}{|c|}{ Total childlessness } \\
\hline & Country name & O.D.C. ${ }^{\mathrm{a}}$ & P.D.C. ${ }^{b}$ & M.D.C. ${ }^{\mathrm{c}}$ & N.S. ${ }^{d}$ & Simulated & Data \\
\hline A & Argentina & 11.0 & 0.3 & 0.9 & 1.9 & 14.0 & 13.8 \\
\hline $\mathrm{m}$ & Bolivia & 1.0 & 2.3 & 0.7 & 1.9 & 5.8 & 6.1 \\
\hline $\mathrm{e}$ & Brazil & 5.4 & 3.5 & 0.8 & 1.9 & 11.6 & 11.9 \\
\hline $\mathrm{r}$ & Chile & 7.0 & 0.0 & 0.3 & 1.8 & 9.1 & 8.9 \\
\hline $\mathrm{i}$ & Colombia & 7.4 & 3.2 & 0.4 & 1.8 & 12.7 & 12.8 \\
\hline c & Costa-Rica & 4.0 & 1.5 & 0.2 & 1.8 & 7.6 & 7.5 \\
\hline \multirow[t]{11}{*}{$\mathrm{a}$} & Dom. Rep. & 1.6 & 2.8 & 0.6 & 1.9 & 6.9 & 7.1 \\
\hline & Ecuador & 4.9 & 2.0 & 0.5 & 1.9 & 9.2 & 10.1 \\
\hline & Haiti & 2.8 & 2.3 & 0.9 & 1.9 & 7.9 & 10.0 \\
\hline & Jamaica & 5.0 & 0.0 & 0.1 & 1.6 & 6.7 & 8.4 \\
\hline & Mexico & 4.0 & 2.7 & 0.3 & 1.9 & 8.9 & 8.9 \\
\hline & Nicaragua & 1.2 & 2.2 & 0.2 & 1.9 & 5.5 & 5.5 \\
\hline & Panama & 1.1 & 2.5 & 0.1 & 1.9 & 5.6 & 5.5 \\
\hline & Peru & 1.3 & 2.0 & 0.2 & 1.9 & 5.4 & 5.9 \\
\hline & Salvador & 3.6 & 3.3 & 0.4 & 1.8 & 9.0 & 9.4 \\
\hline & Uruguay & 9.7 & 0.0 & 0.7 & 1.9 & 12.3 & 12.3 \\
\hline & Venezuela & 5.3 & 0.0 & 0.2 & 1.8 & 7.3 & 8.3 \\
\hline A & Cameroon & 2.3 & 11.8 & 0.8 & 1.8 & 16.7 & 17.8 \\
\hline $\mathrm{f}$ & Ghana & 4.9 & 1.2 & 1.7 & 1.9 & 9.7 & 9.8 \\
\hline $\mathrm{r}$ & Kenya & 0.1 & 1.9 & 0.2 & 1.9 & 4.1 & 4.0 \\
\hline $\mathrm{i}$ & Liberia & 3.0 & 6.9 & 1.2 & 1.9 & 12.9 & 12.7 \\
\hline $\mathrm{c}$ & Morrocco & 2.6 & 0.1 & 0.5 & 2.0 & 5.2 & $5.2^{\mathrm{e}}$ \\
\hline \multirow[t]{9}{*}{$\mathrm{a}$} & Mali & 0.5 & 12.6 & 1.1 & 1.9 & 16.1 & 16.3 \\
\hline & Malawi & 1.0 & 1.1 & 1.4 & 2.0 & 5.5 & 5.9 \\
\hline & Rwanda & 0.0 & 1.8 & 0.1 & 1.9 & 3.8 & 3.5 \\
\hline & Senegal & 0.5 & 2.9 & 0.5 & 1.9 & 5.8 & 6.9 \\
\hline & Sierra Leone & 1.2 & 8.5 & 1.9 & 1.9 & 13.4 & 13.5 \\
\hline & Tanzania & 0.0 & 3.7 & 0.3 & 1.9 & 5.9 & 5.4 \\
\hline & Uganda & 0.1 & 3.1 & 0.7 & 1.9 & 5.8 & 6.0 \\
\hline & South Africa & 1.9 & 3.4 & 0.2 & 1.7 & 7.3 & 8.4 \\
\hline & Zambia & 1.5 & 5.5 & 1.2 & 1.9 & 10.1 & 10.3 \\
\hline A & Indonesia & 0.0 & 1.7 & 0.4 & 2.0 & 4.1 & $4.2^{\mathrm{e}}$ \\
\hline $\mathrm{s}$ & Cambodia & 0.9 & 4.9 & 0.4 & 1.9 & 8.2 & 8.8 \\
\hline $\mathrm{i}$ & Thailand & 3.4 & 0.0 & 1.1 & 2.0 & 6.5 & $5.7^{\mathrm{e}}$ \\
\hline \multirow[t]{2}{*}{$\mathrm{a}$} & Vietnam & 3.3 & 1.8 & 0.2 & 1.9 & 7.2 & 7.2 \\
\hline & Palestine & 2.3 & 0.0 & 0.5 & 2.0 & 4.7 & $4.0^{\mathrm{e}}$ \\
\hline$A L L$ & & 3.5 & 2.3 & 0.5 & 1.9 & 8.2 & 8.3 \\
\hline$D H S$ & & 2.9 & 2.6 & 0.5 & 1.9 & 7.9 & 8.1 \\
\hline
\end{tabular}

Notes: $A L L$ is an aggregate estimation for all 36 countries. DHS provides the aggregated estimates for the childlessness decomposition for countries with data in both DHS and IPUMS.
a. Opportunity-driven childlessness;
b. Poverty-driven childlessness;
c. Mortality-driven childlessness;
d. Natural sterility;
e. Childlessness rates for married only. 

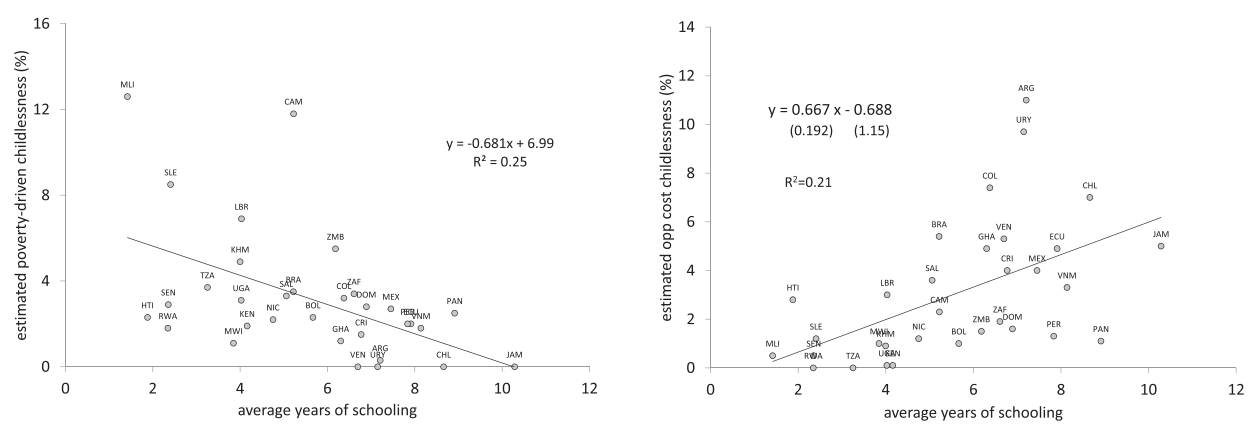

FIGURE 7. Estimates for poverty-driven childlessness (left) and opportunity-driven childlessness (right).

their level of development: Cameroon, Mali, Sierra Leone, and Liberia. These countries belong to a region labeled the African Infertility Belt due to the high prevalence of childlessness. The part of childlessness that is driven by a high opportunity cost emerges along with economic development. A one-year rise in school-life expectancy increases opportunity-driven childlessness by 0.67 percentage points.

Figure 7 confirms the intuitions of Poston and Trent (1982) according to whom, as a country develops, childlessness decreases to a minimum level due to the decrease in subfecundity, and then increases due to reasons that affect the fertility decisions of women in developed economies (high opportunity cost).

\subsection{Comparative Statics}

In addition to decomposing fertility according to its margins, we quantify the impact on completed fertility of four aspects of social progress that come along with development. We study the social progress targeted by most national, international, and nongovernmental organizations: achieving universal primary education, ${ }^{26}$ putting an end to unwanted births, ${ }^{27}$ eradicating child mortality, ${ }^{28}$ and closing the gender wage gap. ${ }^{29}$ We focus on how endogenous adjustments of marriage and childlessness may counterbalance the adjustments of the intensive margins of fertility.

26. The second goal of the Millennium Development Goals was to "ensure that by 2015, children everywhere, boys and girls alike will be able to complete a full course of primary schooling".

27. Fact sheet\# 351 of the World Health Organization states that family planning is key to slowing unsustainable population growth and the resulting negative impacts on the economy, environment, and national and regional development efforts.

28. Target 4.A of the Millennium Development Goals is reducing the under-five mortality rate by twothirds, between 1990 and 2015 .

29. "Achieving our objectives for global development will demand accelerated efforts to achieve gender equality and women's empowerment. Otherwise, peace and prosperity will have their own glass ceiling." (Hillary Clinton, January 2012). 
The completed fertility in the population F can be decomposed as

$$
\mathrm{F}=\mathrm{m}\left(1-\mathrm{C}_{\text {married }}\right) n_{\text {married }}+(1-\mathrm{m})\left(1-\mathrm{C}_{\text {single }}\right) n_{\text {single }},
$$

where $\mathrm{m}$ is the marriage rate, $\mathrm{C}$ is the childlessness rate, and $n$ is the fertility of mothers. The long-term impact of a shock or a policy on completed fertility does not only depend on the effect on the fertility of mothers, but also on how marriage rates and childlessness rates are affected. Figures 8-10 summarize the aggregate implications for $\mathrm{m}, \mathrm{C}$, and $n$ of the four scenarios.

In order to see the importance of endogenous marriage rates and childlessness rates when computing the effect of development on completed fertility, F, we compute the partial change in fertility as

$$
\Delta \mathrm{F}_{\mathrm{p}}=\mathrm{m}\left(1-\mathrm{C}_{\text {married }}\right) \Delta n_{\text {married }}+(1-\mathrm{m})\left(1-\mathrm{C}_{\text {single }}\right) \Delta n_{\text {single }}
$$
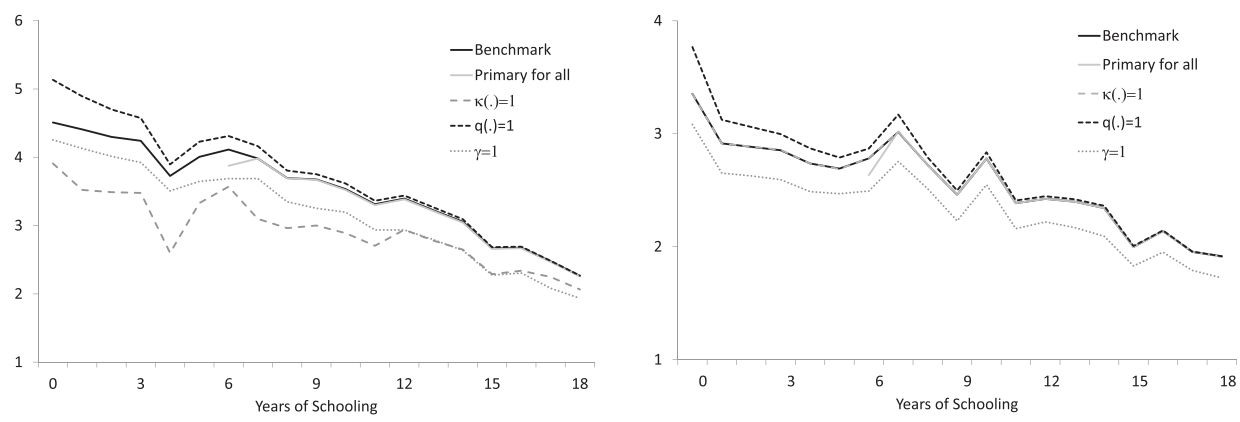

FIGURE 8. Fertility of married (left) and single (right) mothers. Benchmark (black), universal primary education (gray), perfect family planning (dashed gray), no mortality (dashed black), and gender equality (dotted gray).
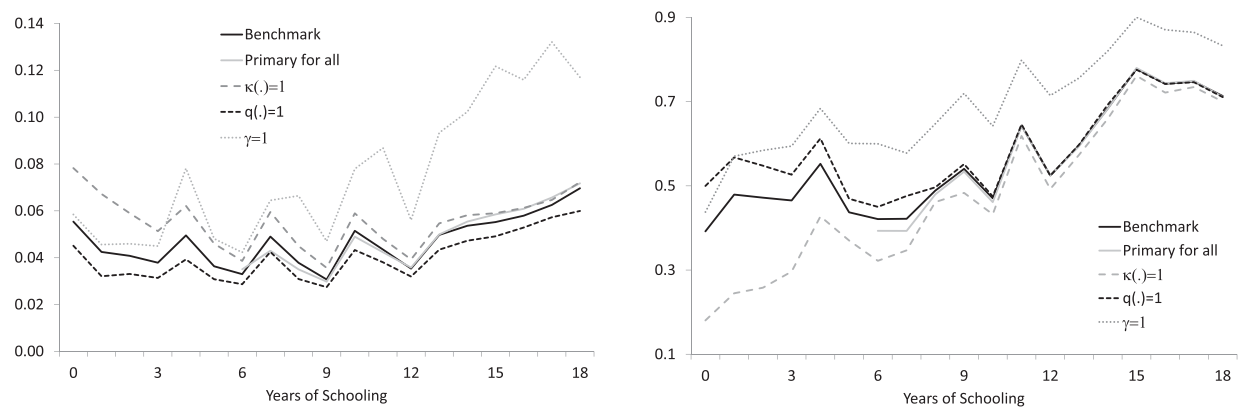

FIGURE 9. Childlessness rates of married (left) and single (right) women. Benchmark (black), universal primary education (gray), perfect family planning (dashed gray), no mortality (dashed black), and gender equality (dotted gray). 

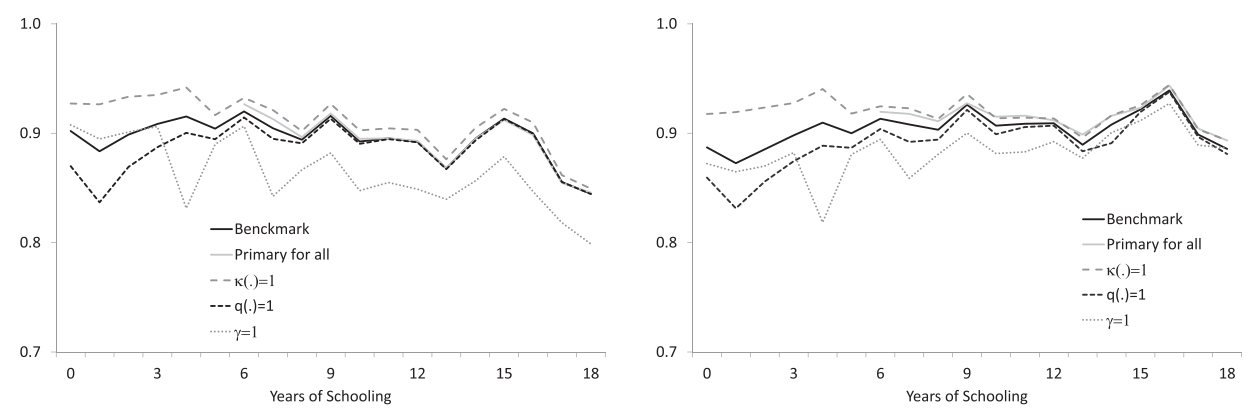

FIGURE 10. Marriage rates of women (left) and men (right). Benchmark (black), universal primary education (gray), perfect family planning (dashed gray), no mortality (dashed black), and gender equality (dotted gray).

and compare it to the total change, which also accounts for changes in marriage and childlessness:

$$
\begin{aligned}
\Delta \mathrm{F}=\Delta \mathrm{F}_{\mathrm{p}}+\left(\left(1-\mathrm{C}_{\text {married }}\right)\right. & \left.n_{\text {married }}-\left(1-\mathrm{C}_{\text {single }}\right) n_{\text {single }}\right) \Delta \mathrm{m} \\
& -\mathrm{m} n_{\text {married }} \Delta \mathrm{C}_{\text {married }}-(1-\mathrm{m}) n_{\text {single }} \Delta \mathrm{C}_{\text {single }} .
\end{aligned}
$$

Table 5 compares the variation in completed fertility predicted by our model $\Delta \mathrm{F}$ to $\Delta \mathrm{F}_{\mathrm{p}} \cdot{ }^{30}$ The latter depicts a situation in which childlessness and marriage rates are fixed to their benchmark values. ${ }^{31}$ We discuss the impact of each change on completed fertility, $\mathrm{F}$, and each of its components, $\mathrm{m}, \mathrm{C}$, and $n$, one by one.

Universal Primary Education. We suppose that everybody is endowed with at least completed primary education. All those who had less than 7 years of schooling in our original simulation now have 7 years. A first impact of this change is reducing povertydriven childlessness drastically. At the aggregate level, poverty-driven childlessness is divided by more than four, receding from $2.3 \%$ in the benchmark to $0.8 \%$ (Table E. 14 in Online Appendix). The reduction of poverty-driven childlessness is quantitatively important in the most affected countries such as Sierra Leone, for which poverty-driven childlessness is reduced from $8.5 \%$ to $4.3 \%$. At the aggregate level, childlessness decreases from $8.2 \%$ to $6.5 \%$ (Table E.14 of the Online Appendix).

The effect of universal primary education on the intensive margin of fertility is also negative due to the increased opportunity cost of child-rearing. Figure 8 indicates that, on average, the fertility of mothers drops because the vast majority

30. For illustration purposes, we show only 17 of the 36 countries. The complete list can be found in Table E.13 of Online Appendix. The countries considered here are those for which we have DHS data on unwanted births, on the fertility of single women, and where there are more than 20,000 married women.

31. As the equilibrium on the marriage market has no impact on individual decisions, this way of calculating the marginal contribution of our mechanisms is valid. 
TABLE 5. Impact on completed fertility (in \%) of social progress in the case where childlessness and marriage are endogenous $(\Delta \mathrm{F} / \mathrm{F})$ and in the case where childlessness and marriage are fixed to their benchmark values $\left(\Delta \mathrm{F}_{\mathrm{p}} / \mathrm{F}\right)$.

\begin{tabular}{|c|c|c|c|c|c|c|c|c|c|}
\hline \multirow[t]{2}{*}{ Country } & \multirow{2}{*}{$\begin{array}{c}\text { Bench } \\
\text { fertility } \\
\text { F }\end{array}$} & \multicolumn{2}{|c|}{$\begin{array}{c}\text { Universal } \\
\text { primary education }\end{array}$} & \multicolumn{2}{|c|}{$\begin{array}{c}\text { Perfect } \\
\text { family planning }\end{array}$} & \multicolumn{2}{|c|}{$\begin{array}{l}\text { No child } \\
\text { mortality }\end{array}$} & \multicolumn{2}{|c|}{$\begin{array}{c}\text { Gender } \\
\text { wage equality }\end{array}$} \\
\hline & & $\Delta \mathrm{F} / \mathrm{F}$ & $\Delta \mathrm{F}_{\mathrm{p}} / \mathrm{F}$ & $\Delta \mathrm{F} / \mathrm{F}$ & $\Delta \mathrm{F}_{\mathrm{p}} / \mathrm{F}$ & $\Delta \mathrm{F} / \mathrm{F}$ & $\Delta \mathrm{F}_{\mathrm{p}} / \mathrm{F}$ & $\Delta \mathrm{F} / \mathrm{F}$ & $\Delta \mathrm{F}_{\mathrm{p}} / \mathrm{F}$ \\
\hline BOL & 4.07 & 0.63 & -0.63 & -10.20 & -11.46 & 11.13 & 17.70 & -4.68 & -4.81 \\
\hline BRA & 3.25 & -4.96 & -7.20 & -29.12 & -30.19 & 1.87 & 4.69 & -13.02 & -7.13 \\
\hline COL & 3.10 & -0.23 & -1.54 & -9.22 & -8.37 & 3.42 & 3.38 & -15.52 & -9.35 \\
\hline DOM & 3.47 & -3.69 & -5.19 & -9.87 & -10.87 & 2.88 & 3.39 & -13.26 & -11.31 \\
\hline HAI & 4.33 & -8.08 & -7.87 & -17.60 & -16.07 & 12.52 & 11.74 & -9.73 & -5.54 \\
\hline NIC & 3.73 & 1.79 & -0.20 & -5.06 & -5.75 & 7.88 & 7.86 & -5.95 & -4.81 \\
\hline PER & 3.68 & 1.30 & -0.10 & -7.55 & -8.01 & 4.91 & 4.96 & -13.91 & -10.78 \\
\hline URY & 2.91 & -0.72 & -1.54 & -28.04 & -28.38 & 2.12 & 1.55 & -25.96 & -6.26 \\
\hline GHA & 3.61 & -6.48 & -8.02 & -24.18 & -23.63 & 6.80 & 6.00 & -11.08 & -6.55 \\
\hline KEN & 5.40 & -0.46 & -1.68 & -8.12 & -9.40 & 8.10 & 11.62 & -5.75 & -6.90 \\
\hline MWI & 4.56 & -4.19 & -4.94 & -16.62 & -15.96 & 12.55 & 19.54 & -6.20 & -5.50 \\
\hline RWA & 5.31 & 2.61 & 1.85 & -7.86 & -9.46 & 14.38 & 28.67 & -0.89 & -2.58 \\
\hline UGA & 5.37 & -2.05 & -3.95 & -11.46 & -12.01 & 3.74 & 14.63 & -2.33 & -3.54 \\
\hline ZAF & 3.69 & 0.73 & -0.84 & -2.72 & -2.83 & 5.91 & 5.52 & -7.00 & -4.37 \\
\hline ZMB & 4.32 & -1.65 & -3.13 & -12.25 & -11.96 & 7.38 & 10.28 & -12.37 & -10.93 \\
\hline KHM & 3.71 & -7.93 & -11.88 & -21.37 & -24.44 & 1.48 & 4.59 & -18.56 & -13.64 \\
\hline VNM & 3.05 & 0.26 & -1.20 & -24.66 & -26.03 & 1.13 & 1.36 & -14.32 & -10.74 \\
\hline ALL & 3.54 & -1.56 & -3.02 & -16.40 & -16.92 & 5.03 & 6.06 & -12.97 & -8.21 \\
\hline DHS & 3.57 & -1.32 & -2.91 & -14.68 & -14.95 & 5.76 & 6.98 & -12.03 & -8.81 \\
\hline
\end{tabular}

of women are now more educated, and that the fertility of mothers decreases with education.

The comparison between $\Delta \mathrm{F} / \mathrm{F}$ and $\Delta \mathrm{F}_{\mathrm{p}} / \mathrm{F}$ in Table 5 brings an important result. At the aggregate level, completed fertility would be reduced by $3.02 \%$ if marriage and childlessness were invariant. Including these two margins divides this effect by more than two as the final reduction of completed fertility is only $1.56 \%$. Nevertheless, there is a strong heterogeneity across countries, which we can break down into three main situations. For the first group of countries, the endogeneity of childlessness and marriage weakens the negative impact of the generalization of primary education on mothers' fertility, as we see on average. This happens, for instance, in Brazil, Ghana, Malawi, and Cambodia where it reduces completed fertility, in line with the predictions of the standard Beckerian fertility models. For the second group of countries, the impact of generalizing education on the intensive margin of fertility is negative, but including the effects on childlessness and marriage rates makes completed fertility increase. This is the case for instance in Bolivia, Nicaragua, South Africa, or Vietnam. The last group is composed of countries that are strongly affected by Malthusian behaviors like Rwanda, where the generalization of education increases the fertility of mothers; this rise is magnified by the reduction of poverty-driven childlessness.

We conclude that generalizing primary education reduces poverty-driven childlessness and only has a limited effect on completed fertility. To the best of our knowledge, such a result has not yet been underlined in the economic literature that 
has not considered endogenous childlessness and marriage to discuss the impact of education on fertility in developing countries.

Perfect Family Planning. The second type of progress concerns a fully efficient contraceptive behavior in developing countries. For the sake of illustration, we set the percentage of couples able to control fertility $\kappa$ equal to 1 , making unwanted births disappear. The fertility of married mothers accordingly decreases and the childlessness of married women increases, in particular for the low educated (left panels of Figures 8 and 9). When married women do not have unwanted births, there is less uncertainty concerning the outcome of marriage (mortality remains) and everybody is also more willing and likely to marry, especially the low educated who incurred a higher risk (the dashed gray line of Figure 10 is above the black line). The rise in marriage rates decreases childlessness rates among low-educated single women (right panel of Figure 9). This happens because marrying a low-educated woman becomes less risky. A selection into marriage occurs among low-educated women; those with the lowest nonlabor income are more prone to accept marriage than those with a high nonlabor income (who rely less on marriage to be protected against poverty and poverty-driven childlessness). This selection leaves low-educated women who are less concerned with poverty-driven childlessness single. This reduces the prevalence of poverty-driven childlessness among single women. On the whole, poverty-driven childlessness slightly decreases from $2.3 \%$ to $2.1 \%$ at the aggregate level (Table E.15 of the Online Appendix).

Taking all these effects into account, eliminating unwanted births lowers completed fertility from 3.54 to 2.96 children per woman on average for all countries. This drop of 0.58 children lies at the lower bound of prediction of May (2012) concerning the efficiency of family planning on reducing fertility. Our structural approach clearly argues in favor of a prudent estimation of the efficiency of family planning.

At the country level, we find that the effect of perfect family planning on total fertility is always negative, but differs across countries. In countries where the percentage of unwanted births is high (for instance, Peru, Rwanda, or Vietnam), then the effect of family planning on completed fertility is lower when endogenous responses of childlessness and marriage are accounted for than when they are not. In other countries, such as Colombia, Haiti, Ghana, Malawi, and Zambia, the endogenous adjustments of childlessness and marriage magnify the impact of family planning policies. In these countries, the prevalence of unwanted births is relatively high among highly educated women. Thus, if they no longer experience unwanted births, a significant share of these women remain childless because of the high opportunity cost, which diminishes completed fertility. ${ }^{32}$

32. This result is in line with Baudin and Gobbi (2016, Chap. 24) who argue that nowadays, most African countries need population policies that affect the deep determinants of fertility rather than the proximate ones, whereas this is not the case in Asian countries like Vietnam. The main reason behind this result is 
Notice that perfect family planning technology does not necessarily reduce completed fertility the most in places where unwanted births are most common. For instance, in Bolivia, on average women have a higher probability of having unwanted births than in Brazil (0.37 against 0.28 from Table A.2), but family planning reduces completed fertility by $10.2 \%$ in Bolivia and by $29.1 \%$ in Brazil. This is because although more Bolivian women can choose their fertility optimally, Brazilians decrease their fertility more strongly.

Eradication of Child Mortality. Let us now consider how eliminating child mortality $(q(\cdot)=1)$ affects completed fertility. Figure 8 shows that the reduction of mortality increases the fertility of mothers, in particular for the poorly educated. The effect is of the order of half a child for a mother with no education. In addition to this effect, marriage and childlessness rates vary. Childlessness among married women decreases, whereas it increases among single women (Figure 9). The explanation we can derive from the theory is the following. Child mortality rates are higher among poorly educated women who are also more likely to experience unwanted pregnancies. Child mortality then "helps" families who have more children than what is optimal to regulate their size. A reduction in mortality rates then increases the risk in terms of potential consumption loss for males from marrying low-educated women; this is especially important for poor males. This makes a man less likely to accept a marriage offer from a low-educated woman, but it also means that a low-educated woman is less likely to accept any offer (Figure 10). Indeed, when single, a woman does not have unwanted births. This implies that low-educated women are more likely to be single and hence childless. The theory predicts that poverty-driven childlessness increases from $2.3 \%$ to $5.8 \%$ after this shock (Table E.16 of the Online Appendix). This highlights an interesting mechanism regarding how mortality allows to regulate fertility. This mechanism is in line with Malthusian theory according to which child mortality has some "virtues". Without better family planning, reductions in child mortality can therefore be costly for poor women.

At the aggregate level, completed fertility increases from 3.57 to 3.78 (fertility increases on the intensive margin but decreases on the extensive margin). Including the effects on marriage and childlessness rates decreases the impact that the intensive margin of fertility has on completed fertility. Eradicating child mortality has a limited impact on completed fertility at the aggregate level, but a dramatic one in countries that are strongly concerned by child mortality. For example, in Brazil, the disappearance of child mortality increases completed fertility by $1.9 \%$ when accounting for the changes in marriage and childlessness rates, whereas otherwise we predicted an increase of 4.7\%. The difference is even bigger in Rwanda, where child mortality is the most prevalent. In Rwanda, eradicating child mortality increases completed fertility by 0.76 children. Childlessness in Rwanda increases with the drop in mortality mainly because

that African countries have been the main recipients of family planning programs over the last decades. DHS data shows indeed that unwanted births are much more prevalent in Vietnam than in Mali. 
of poverty-driven childlessness, which increases from $1.8 \%$ to $12.4 \%$ (Table E.16 of the Online Appendix). This counteracts the rise in the fertility of mothers that, alone, would have increased completed fertility by 1.52 children per woman. Hence, our theory predicts that, in some countries, the eradication of mortality goes hand in hand with an increase in poverty-driven childlessness, which reflects a pauperization among uneducated women.

The impacts of an eradication of child mortality together with better family planning on completed fertility stress the importance of uncertainty for family decisions such as marriage and fertility.

Female Empowerment. The last comparative static exercise that we consider removes the gender wage gap on the labor market. To fix ideas, this implies that $\gamma$ goes from 0.79 to 1.00 in the average country (but from 0.67 to 1.00 in Morocco, which is the country with the strongest gender gap). In other words, gender equality becomes similar to that in Iceland all over the world. ${ }^{33}$ Beyond making women richer, such a change also increases women's bargaining power $\theta$. In this last sense, it empowers women within their couple. ${ }^{34}$

The first direct effect of female empowerment is to make women relatively richer than in the benchmark. This implies that the gains from marriage are lower and hence, women marry less, except those who are very low educated (Figure 10, left panel). The effect on fertility rates is negative due to a higher opportunity cost of raising children for both single and married women (Figure 8). In addition, Figure 9 shows that the effect on childlessness is positive for all categories of women; it is almost absent for the low educated, but strong for the highly educated. From Table E.16 of the Online Appendix, we learn that, on average, closing the gender wage gap increases total childlessness from $8.2 \%$ to $12.0 \%$. Opportunity-driven childlessness rises from $3.5 \%$ to $7.2 \%$ and poverty-driven childlessness declines from $2.3 \%$ to $1.8 \%$. At the country level, the overall impact on childlessness depends on whether the decline in poverty-driven childlessness compensates for the increase in opportunity-driven childlessness. In Mali, for example, closing the gender wage gap decreases poverty-driven childlessness from $12.6 \%$ to $7.6 \%$ and increases opportunity-driven childlessness from $0.5 \%$ to $4.8 \%$, making childlessness rates remain unchanged.

Overall, smaller gender wage gaps prove to be very effective in reducing fertility rates. Here, we highlight a channel, childlessness, which amplifies the effect of the intensive margin on average fertility, for most countries, and in particular for those where the opportunity-driven part of childlessness is large. In some few countries,

33. Notice that the gender equality we deal with is of the type "economic participation and support", and is not related to "educational attainment", or to "health and survival", which are other important dimensions of gender discrimination.

34. Another way to empower women consists in sharing child-rearing time equally between women and men. To analyze this policy in a meaningful way, one should model the time use choice of households (see Gobbi 2018 on this issue). 
where poverty-driven childlessness matters more, like Bolivia, Kenya, Rwanda, or Uganda, the reduction of poverty-driven childlessness however hampers the effect of a lower gender wage gap on fertility compared to what it would be if only the intensive margin of fertility changed.

\section{Conclusion}

We look at the extensive margin of fertility, how it changes with economic development, and how the impact of social changes on completed fertility is nuanced when accounting for the different reasons why women are childless.

Childlessness is endogenous to development. In the poorest countries, it is mostly driven by poverty, which reflects situations in which the fecundity of women is affected, thus leaving them childless. This situation echoes Malthus's preventive check. In more developed countries, women remain childless mainly because the opportunity cost in terms of foregone labor income is high.

We propose a methodology that allows us to distinguish between the different reasons for women's childlessness. It is based on estimating the structural parameters of an economic model in which both men and women decide whether to marry and how many children to have. This estimation is carried out by a simulated method of moment, in which the empirical moments used in the estimation include the fertility of mothers, childlessness, and marriage rates for 36 developing countries.

Comparing the breakdown of childlessness into its causes across countries, we show that when a country develops, poverty-driven childlessness diminishes. However, opportunity-driven childlessness rises, driven by the high opportunity cost of having children for more educated individuals.

The endogeneity of childlessness matters for the impact of development on completed fertility, and therefore, on population growth. Imposing universal primary education is commonly expected to reduce fertility in developing countries. We find that indeed it has a negative impact on the intensive margin of fertility, but that it also makes poverty-driven childlessness less likely. On average, fertility rates may not decrease after such a change and will probably increase in countries where Malthusian checks are still at play nowadays.

Family planning strongly diminishes completed fertility on average, even when we include how it affects marriage and childlessness. This confirms the usual effect advocated by development agencies. However, at the country level, marriage and childlessness can diminish the negative impact that family planning has on completed fertility. This is because marriage rates increase and poverty-driven childlessness decreases, as low-educated women can now more easily find a husband.

Higher gender equality on the labor market also has a strong negative impact on completed fertility. On average, it is magnified by the response of childlessness due to the increase in opportunity-driven childlessness. In the least developed countries, this is not the case though, as the drop in poverty-driven childlessness may counteract the effect on the intensive margin of fertility. 


\section{Appendix A: Details on the Data}

\section{A.1. IPUMS-International}

Country Selection. We select all the latest censuses available in IPUMS International that include the variables "years of schooling" and both "children ever born" and "children surviving".

Some countries were previously selected and dropped afterwards. This is the case of Guinea and Nepal. We dropped the 1996 Guinea census data because it did not allow women to give a polygynous response to the question on marriage. Consequently, $0 \%$ of women aged 40-54 were reported as being in a polygynous marriage, whereas $45.6 \%$ of men were (see Table E. 2 of the Online Appendix). This prevents us from distinguishing between monogamous unions (on which we focus the analysis) and polygynous unions. The $2001 \mathrm{Nepal}$ census data used to be in IPUMS international but was removed because of sampling weight errors.

For South Africa, the "Community Survey 2007" has information on the three variables "years of schooling", "children ever born", and "children surviving". We use the census of 2001 instead as it provides information for $10 \%$ of the population (instead of 2\%). Moreover, in the 2007 community survey, the number of children ever born seems to be inverted with the number of children that survived for a substantial number of women (2,712 women aged between 40 and 54 have more children that survived than ever born). Given that these are crucial variables for our analysis, this guided our choice in selecting the census rather than the community survey.

Finally, IPUMS recently added the 2011 census for Costa Rica. Since the details are not yet provided in the "sample characteristics" webpage (https://international. ipums.org/international/sample_designs/sample_designs_cr.shtml), we decided not to update our data.

Marital Types and Multifamily Households. The proportion of men and women in each type of marital status, by country, can be found in Table E.2 of the Online Appendix.

Polygyny is present in Cameroon, Kenya, Liberia, Mali, Rwanda, Senegal, Sierra Leone, and Uganda. The highest percentages of polygynous unions among women are $50.6 \%$ in Senegal and $46.5 \%$ in Mali. The fertility of mothers involved in monogamous unions is slightly higher than that of women involved in polygynous unions. Childlessness is in general higher for polygynous women.

The 2002 Rwanda Census data shows that $30.3 \%$ of $40-54$ year old women were widowed (compared to $3.9 \%$ for men). This is much higher than in any other country. Our results for Rwanda may therefore suffer from some biases, as dropping $30 \%$ of the sample may induce a large selection bias. Another extreme case is the Dominican Republic, where $25.8 \%$ of women are in the separated/divorced/spouse absent category. Among these, $70.7 \%$ are separated from a consensual union.

Multifamily households, even though they exist, are not the norm for any level of education. $95.2 \%$ of women in our sample are in a household composed of only one family. The percentage is however lower in some specific countries. In Rwanda, 
TABLE A.1. Census data and number of (unweighted) observations.

\begin{tabular}{|c|c|c|c|c|c|c|}
\hline \multirow{2}{*}{$\begin{array}{l}\text { Country } \\
\text { code }\end{array}$} & \multirow[t]{2}{*}{ Country name } & \multirow[t]{2}{*}{ Year } & \multicolumn{2}{|c|}{ Number of men } & \multicolumn{2}{|c|}{ Number of women } \\
\hline & & & Single & Married & Single & Married \\
\hline ARG & Argentina & 1991 & 46,379 & 426,773 & 26,991 & 258,630 \\
\hline BOL & Bolivia & 2001 & 8,290 & 64,465 & 5,093 & 37,566 \\
\hline BRA & Brazil & 2000 & 80,626 & $1,010,146$ & 56,802 & 564,511 \\
\hline $\mathrm{CHL}$ & Chile & 2002 & 27,772 & 160,298 & 21,439 & 97,221 \\
\hline COL & Colombia & 2005 & 85,217 & 381,504 & 48,497 & 200,283 \\
\hline CRI & Costa Rica & 2000 & 5,141 & 36,467 & 3,704 & 19,904 \\
\hline DOM & Dominican Republic & 2010 & 12,419 & 98,769 & 2,596 & 47,895 \\
\hline ECU & Ecuador & 2010 & 18,517 & 132,191 & 12,961 & 74,013 \\
\hline HTI & Haiti & 2003 & 6,781 & 62,523 & 3,310 & 38,288 \\
\hline $\mathrm{JAM}^{\mathrm{a}}$ & Jamaica & 2001 & 7,449 & 13,907 & 3,347 & 5,292 \\
\hline MEX & Mexico & 2010 & 94,945 & $1,042,567$ & 79,231 & 685,238 \\
\hline NIC & Nicaragua & 2005 & 5,520 & 40,876 & 3,207 & 20,679 \\
\hline PAN & Panama & 2010 & 8,059 & 36,328 & 2,870 & 19,506 \\
\hline PER & Peru & 2007 & 37,697 & 272,159 & 17,747 & 158,823 \\
\hline SAL & El Salvador & 2007 & 8,460 & 50,713 & 7,955 & 26,518 \\
\hline URY & Uruguay & 1996 & 3,895 & 30,167 & 2,007 & 18,306 \\
\hline VEN & Venezuela & 2001 & 43,288 & 215,939 & 24,189 & 113,766 \\
\hline CAM & Cameroun & 2005 & 10,861 & 77,613 & 9,406 & 41,470 \\
\hline GHA & Ghana & 2010 & 10,734 & 177,005 & 5,158 & 111,832 \\
\hline KEN & Kenya & 1999 & 3,408 & 58,019 & 3,194 & 38,857 \\
\hline LBR & Liberia & 2008 & 3,292 & 20,460 & 1,773 & 11,222 \\
\hline MAR & Morocco & 2004 & 6,926 & 126,201 & 8,832 & 88,500 \\
\hline $\mathbf{M L I}^{\mathrm{a}}$ & Mali & 2009 & 2,580 & 45,461 & 1,435 & 19,505 \\
\hline MWI & Malawi & 2008 & 1,408 & 66,764 & 727 & 40,179 \\
\hline RWA & Rwanda & 2002 & 1,699 & 37,269 & 1,380 & 22,497 \\
\hline SEN & Senegal & 2002 & 3,088 & 47,298 & 1,504 & 17,971 \\
\hline SLE & Sierra Leone & 2004 & 4,976 & 31,750 & 1,552 & 12,095 \\
\hline TZA & Tanzania & 2002 & 13,385 & 208,581 & 9,255 & 127,062 \\
\hline UGA & Uganda & 2002 & 8,258 & 109,317 & 3,168 & 51,260 \\
\hline $\mathbf{Z A F}^{\mathrm{b}}$ & South Africa & 2001 & 53,426 & 256,875 & 48,298 & 141,424 \\
\hline ZMB & Zambia & 2010 & 1,897 & 56,025 & 1,460 & 36,646 \\
\hline IDN & Indonesia & 1995 & 679 & 55,683 & 1,019 & 39,049 \\
\hline KHM & Cambodia & 2008 & 2,219 & 116,660 & 5,513 & 83,624 \\
\hline THA & Thailand & 2000 & 3,355 & 63,908 & 3,983 & 42,815 \\
\hline $\mathbf{V N M}^{\mathrm{a}}$ & Vietnam & 2009 & 20,335 & 1134199 & 41,053 & 746,960 \\
\hline WBG & Palestine & 1997 & 202 & 15,217 & 837 & 8,711 \\
\hline & Total & & 653,183 & $6,780,097$ & 471,493 & $4,068,118$ \\
\hline
\end{tabular}

Notes: Country code in bold indicates the countries for which DHS samples are available. The age range of men differs by country according to Table E. 1 of the Online Appendix.

a. Countries where women are aged 40-49;

b. Countries where women are aged 40-50.

Senegal and Tanzania, the percentage of women who are in households composed by more than one family is respectively $19.9 \%, 20.9 \%$, and $22.5 \%$. In these three countries, half of those women living in households composed by more than one family did not go to school (so it's around 10\% among the "no school" of these countries). Among singles, $90.1 \%$ of women live in a one family type household. 
Education Levels. For some of the countries in the sample, the variable on years of schooling had a top code of 12 or 13 . For these countries, we added 2 years of schooling to the required number of years to achieve high school for individuals who had completed secondary education and had a postsecondary technical education or completed some college. For those who had completed university, we added 4 years of schooling.

More precisely, Cambodia, Kenya, Nigeria, Sierra Leone, South Africa, and Zambia have a top code of 13 years of schooling. For all these countries, we give 16 years of schooling to all the observations who completed university. In Cambodia, Nigeria and Zambia, we give a value of 14 years of schooling to those who had a postsecondary technical education. Peru's top code is 12 . We give 13 years of schooling to those who had a postsecondary technical education and 15 years to those who had completed university. Bolivia, Brazil, Indonesia, Liberia, and Palestine have a top code of 17 years. We do not change the classification for these countries. For Haiti, there were observations coded as having completed secondary education but with less than 11 years of schooling. We dropped these observations. For Jamaica, we dropped: the observations with more than 5 years of schooling and coded as having completed less than primary education, the observations with less than 6 years of schooling and coded as having completed primary, the observations with less than 11 years of schooling and coded as having completed secondary, and the observations with less than 14 years of schooling and coded as having completed university.

Tables E.10 and E.11 of the Online Appendix show the final education shares for each country.

Mistakes. We drop women who had declared to have less children born than children that survived from the sample. This concerns one observation in Jamaica and Uruguay, 715 observations in Senegal and 14 observations in Vietnam.

\section{A.2. DHS data}

For more than two decades, demographers have discussed the way to measure the difference between desired and completed fertility. The debate between Pritchett (1994a, b) and Bongaarts (1994b) about undesired births has been magnified by their opposition on the need for family planning programs in developing countries. These authors have focused on the proportion of births that are not desired, paying however little, or even no attention to the proportion of women experiencing unwanted births that is what we focus on in this paper.

Here we provide six alternative measures of "uncontrolled fertility". For estimating all the measures, we have only considered monogamous married women.

A.2.1. Different Measures. The first measure we propose considers that a woman, over 40, is unable to control fertility if the number of children ever born to her is at least two more children than her declared ideal number. ${ }^{35}$ Under this measure (measure 1),

35. The ideal number of children is given as the answer to "[What is] The ideal number of children that the respondent would have liked to have in her whole life, irrespective of the number she already has." 
TABLE A.2. Alternative measures of uncontrolled fertility—data from DHS.

\begin{tabular}{|c|c|c|c|c|c|c|c|c|c|}
\hline \multirow[t]{2}{*}{ Country } & \multirow[t]{2}{*}{ Year } & \multicolumn{6}{|c|}{ Measures } & \multicolumn{2}{|c|}{$\begin{array}{l}\text { Regression } \\
\text { coefficient }\end{array}$} \\
\hline & & 1 & 2 & 3 & 4 & 5 & 6 & $a_{j} * 10$ & $b_{j}$ \\
\hline BOL & 2008 & 0.713 & 0.374 & 0.313 & 0.207 & 0.696 & 0.314 & -0.018 & 0.419 \\
\hline BRA & 1996 & 0.491 & 0.281 & 0.238 & 0.141 & 0.548 & 0.273 & -0.025 & 0.436 \\
\hline $\mathrm{COL}$ & 2010 & 0.385 & 0.236 & 0.159 & 0.033 & 0.464 & 0.282 & -0.028 & 0.462 \\
\hline DOM & 2007 & 0.334 & 0.165 & 0.129 & 0.036 & 0.358 & 0.031 & -0.017 & 0.274 \\
\hline ECU & 1987 & 0.609 & & & 0.246 & 0.299 & & & \\
\hline HTI & 2012 & 0.693 & 0.335 & 0.278 & 0.193 & 0.497 & 0.275 & -0.022 & 0.420 \\
\hline MEX & 1987 & 0.665 & & & 0.319 & 0.720 & & & \\
\hline NIC & 2001 & 0.639 & 0.347 & 0.303 & 0.217 & 0.572 & 0.150 & -0.019 & 0.419 \\
\hline PER & 2012 & 0.540 & 0.392 & 0.307 & 0.085 & 0.479 & 0.307 & -0.031 & 0.602 \\
\hline GHA & 2008 & 0.388 & 0.239 & 0.159 & 0.032 & 0.256 & 0.409 & -0.014 & 0.305 \\
\hline KEN & 2008-2009 & 0.539 & 0.294 & 0.237 & 0.108 & 0.394 & 0.214 & -0.004 & 0.305 \\
\hline LBR & 2013 & 0.427 & 0.145 & 0.105 & 0.069 & 0.144 & 0.139 & -0.007 & 0.183 \\
\hline MAR & 2003-2004 & 0.588 & 0.373 & 0.264 & 0.133 & 0.379 & 0.396 & -0.025 & 0.443 \\
\hline MLI & 2012-2013 & 0.349 & 0.075 & 0.048 & 0.030 & 0.078 & 0.092 & -0.007 & 0.116 \\
\hline MWI & 2010 & 0.572 & 0.315 & 0.260 & 0.124 & 0.416 & 0.184 & -0.025 & 0.372 \\
\hline RWA & 2010 & 0.686 & 0.516 & 0.432 & 0.157 & 0.309 & 0.376 & -0.015 & 0.576 \\
\hline SEN & 2012-2013 & 0.416 & 0.045 & 0.027 & 0.041 & 0.122 & 0.055 & -0.003 & 0.057 \\
\hline SLE & 2013 & 0.347 & 0.082 & 0.045 & 0.050 & 0.059 & 0.09 & -0.005 & 0.118 \\
\hline UGA & 2011 & 0.568 & 0.223 & 0.191 & 0.122 & 0.373 & 0.149 & -0.007 & 0.252 \\
\hline ZAF & 1998 & 0.366 & 0.201 & 0.116 & 0.033 & 0.372 & 0.197 & -0.011 & 0.265 \\
\hline ZMB & 2007 & 0.443 & 0.200 & 0.157 & 0.090 & 0.298 & 0.175 & -0.003 & 0.189 \\
\hline IDN & 2012 & 0.316 & 0.185 & 0.108 & 0.026 & 0.224 & 0.276 & -0.007 & 0.211 \\
\hline KHM & 2010 & 0.420 & 0.260 & 0.174 & 0.050 & 0.235 & 0.292 & -0.019 & 0.339 \\
\hline THA & 1987 & 0.602 & & & 0.088 & 0.402 & & & \\
\hline VNM & 2002 & 0.490 & 0.419 & 0.211 & 0.026 & 0.354 & 0.549 & -0.024 & 0.537 \\
\hline
\end{tabular}

TABLE A.3. Countries coupled when there was no data on unwanted births in DHS.

Missing countries $\rightarrow$ Used countries Missing countries $\rightarrow$ Used countries

$\begin{array}{cc}\mathrm{ARG} \rightarrow \mathrm{BRA} & \mathrm{SAL} \rightarrow \mathrm{NIC} \\ \mathrm{CHL} \rightarrow \mathrm{DOM} & \mathrm{URY} \rightarrow \mathrm{NIC} \\ \mathrm{CRI} \rightarrow \text { NIC } & \mathrm{VEN} \rightarrow \mathrm{DOM} \\ \mathrm{ECU} \rightarrow \mathrm{DOM} & \mathrm{CAM} \rightarrow \mathrm{KEN} \\ \mathrm{JAM} \rightarrow \mathrm{BOL} & \mathrm{TZA} \rightarrow \mathrm{KEN} \\ \mathrm{MEX} \rightarrow \text { NIC } & \mathrm{THA} \rightarrow \mathrm{KHM} \\ \mathrm{PAN} \rightarrow \text { NIC } & \mathrm{WBG} \rightarrow \mathrm{KHM}\end{array}$

half of the women are unable to control fertility. One major weakness of this measure is that the difference between the number of children ever born and the ideal number of children can be the outcome of a rational choice. It could, for instance, reflect that the husband has a higher ideal number of children together with a higher bargaining

We then use the number of births rather than with the number of surviving children because it includes the children who did not survive. 
position. $^{36}$ Measure 2 accounts for this weakness and is the one we choose for the estimation. To account for the perceived desired fertility of husbands, we use the answer to "whether the respondent believes her partner wants the same number of children, more children or fewer children than she wants herself". ${ }^{37}$ Measure 3 uses the same definition as measure 2 except that the differential between completed fertility and the ideal number of children must be at least three instead of two.

Measure 4 relies on the idea that a woman who does not control fertility has a very large number of children ever born. This measure is simply the percentage of women over 40 who had at least nine children while their ideal number of children is below or equal to four. The percentages are small compared to alternative measures. The correlation between measures 1 and 4 equals 0.84 .

To account for ex post rationalization bias, we propose measure 5 and measure 6 . Measure 5 focuses on women aged between 35 and 40 who had a birth within the last three/five years before the DHS study. ${ }^{38}$ We consider that these women did not control fertility if they answered "not at all" to the question of whether the child born in the last three/five years was wanted at the time, later or not at all (question v367). The correlation between measures 1 and 5 equals 0.67 .

Measure 6 relaxes measure 2 by assuming that a woman does not control fertility if she had at least one more child than her declared ideal number. Using measure 2 instead of measure 2 leads to the estimations presented in Appendix D. Interestingly enough, reducing the number of extra births from 2 to 1 does not necessarily mean that the probability for not controlling fertility is higher. Let $A_{1}$ be the event "having at least one child more than the ideal number" and $A_{2}$ "having at least two child more than the ideal number". As $A_{2} \subset A_{1}$, we know that $P\left(A_{1}\right)>P\left(A_{2}\right)$. Let $B$ denote the event "husband doesn't want more children than I do". What we measure with our uncontrolledness concept is simply $P\left(A_{n} \cap B\right)$. Then we have

$$
\begin{aligned}
& P\left(A_{1} \cap B\right)=P\left(B \mid A_{1}\right) P\left(A_{1}\right), \\
& P\left(A_{2} \cap B\right)=P\left(B \mid A_{2}\right) P\left(A_{2}\right) .
\end{aligned}
$$

In our dataset, we find $P\left(A_{1} \cap B\right)<P\left(A_{2} \cap B\right)$ what is satisfied if

$$
P\left(B \mid A_{1}\right)<\frac{p\left(A_{2}\right)}{p\left(A_{1}\right)} P\left(B \mid A_{2}\right) .
$$

Even if $\left(p\left(A_{2}\right) / p\left(A_{1}\right)\right)<1$, the previous condition can be fulfilled and requires that the probability to share the same ideal number of children with husband is much smaller among women having only one more child than her ideal number of children

36. Ashraf et al. (2014) find that facilitating family planning services reduces births, in particular among women having a husband who desires more children than themselves.

37. Responses for beliefs regarding husbands fertility intentions is not available for Ecuador, Mexico, and Thailand. Across the remaining 22 countries where data about male's perceived desires are available, we find that the coefficient of linear correlation between measures 1 and 2 is 0.77 .

38. We do not include very young women because the probability for a woman who is not able to control fertility of facing an unwanted birth increases with age. 
than among those who have at least 2 more children than her ideal number of births. Measure 6 may nevertheless correct for the ex post rationalization bias as now, even if a woman increases her ideal number of children to make it close to her actual number, the only possibility for her not to be considered as not controlling her fertility is to make both numbers equal.

A.2.2. Missing Countries. For some countries listed in Table A.1, the data needed to calculate measure 2 are not available. For these countries, we use the estimates of the "closest country" with respect to the pattern of the completed fertility of married mothers, by years of schooling. In practice, we regressed the means of the completed fertility of married mothers for each year of schooling of the country lacking DHS data on unwanted births on the completed fertility of married mothers for each year of schooling of another country with DHS data on unwanted births, on the same continent. These means were taken from our samples from IPUMS international. In the regression, we used the number of observations by years of schooling of the country lacking DHS data as weights. The "closest country" was the one for which the $R^{2}$ was the highest. Table A. 3 shows the countries for which there was no data on unwanted births in DHS in the "missing countries" column and the countries for which we used the estimates in the "used countries" column. ${ }^{39}$

A.2.3. Predicted Values for all Education Levels. DHS provides two measures of educational attainment, respectively close to years of schooling and educational attainment in IPUMS International. Our exploration of these data gave us more confidence in the variable similar to educational attainment, which divides the population into four education categories: "no school", "primary education", "secondary education" and "higher education". To obtain values for all years of educations, the following linear regression model appears to be the best bivariate regression model of the percentage of women who do not control fertility $1-\kappa_{j}\left(e_{i}\right)$ :

$$
1-\kappa_{j}\left(e_{i}\right)=a_{j} e_{i}+b_{j}+\varepsilon_{i j}
$$

where $i$ denotes a woman, $j$ a country, and $\varepsilon_{i j} \sim \mathcal{N}\left(0, \sigma_{j}^{2}\right)$. Table A.2 shows the estimated values of $a_{j}$ and $b_{j}$ for all the countries for which we have the data. For countries for which that data is missing, we use the estimates of the "closest country" as explained in Appendix A.2.2. The gradient of the relationship between the probability of not controlling her fertility and the woman's education is always significantly negative. ${ }^{40}$ Final probabilities of being a woman who cannot control fertility, by country and education are provided in Table E.12 of the Online Appendix.

39. For Cameroon the estimate of the coefficient relating education to the probability of not controlling fertility was positive. This is not plausible so we decided to use the estimate for Kenya.

40. The correlation between our measure of uncontrolled fertility and the $\%$ of desired fertility proposed in Pritchett (1994a, pp. 44-45) for the countries included in both studies equals 0.66. 


\section{A.3. Gender Wage Gap, by Country}

TABLE A.4. Average education, female and male, and gender wage gaps by country.

\begin{tabular}{lrrllcll}
\hline & $e_{f}$ & $e_{m}$ & $\gamma$ & & $e_{f}$ & $e_{m}$ & $\gamma$ \\
\hline ARG & 7.83 & 7.79 & 0.82 & GHA & 5.44 & 7.79 & 0.79 \\
BOL & 5.46 & 7.53 & 0.84 & KEN & 3.83 & 5.44 & 0.78 \\
BRA & 5.97 & 5.77 & 0.80 & LBR & 2.42 & 6.08 & $0.79^{\text {a }}$ \\
CHL & 9.40 & 9.49 & 0.76 & MAR & 2.15 & 3.60 & 0.67 \\
COL & 7.30 & 6.87 & 0.82 & MLI & 1.08 & 1.78 & 0.67 \\
CRI & 7.54 & 7.50 & 0.83 & MWI & 3.15 & 5.24 & $0.79^{\text {a }}$ \\
DOM & 8.05 & 7.37 & 0.79 & RWA & 1.99 & 3.22 & 0.78 \\
ECU & 8.90 & 8.80 & $0.79^{\mathrm{a}}$ & SEN & 2.18 & 3.07 & $0.79^{\mathrm{a}}$ \\
HTI & 1.59 & 2.60 & 0.78 & SLE & 1.79 & 3.44 & 0.78 \\
JAM & 11.34 & 10.47 & 0.81 & TZA & 2.82 & 4.29 & 0.79 \\
MEX & 8.16 & 8.48 & 0.79 & UGA & 2.96 & 5.33 & 0.81 \\
NIC & 5.31 & 5.40 & 0.88 & ZAF & 6.65 & 6.86 & 0.86 \\
PAN & 10.03 & 9.39 & 0.82 & ZMB & 5.53 & 7.79 & 0.72 \\
PER & 7.96 & 9.20 & 0.78 & IDN & 4.82 & 5.91 & 0.76 \\
SAL & 5.59 & 6.25 & 0.76 & KHM & 3.27 & 5.24 & 0.75 \\
URY & 8.16 & 7.43 & 0.78 & THA & 4.83 & 5.55 & 0.79 \\
VEN & 7.39 & 7.28 & 0.81 & VNM & 8.00 & 8.50 & 0.79 \\
CAM & 5.14 & 6.22 & 0.75 & WBG & 6.12 & 8.03 & $0.79^{\text {a }}$ \\
\hline
\end{tabular}

Note: a. We used the average of the sample value for the respective countries, due to a lack of information.

\section{Appendix B: Identification}

\section{B.1. Assortative Matching}

The distribution of women and men across the 19 education categories, given in Tables E.10 and E.11 of the Online Appendix are described by the vectors $s^{f}$ and $s^{m}$.

The meeting matrix $\boldsymbol{M}$ is a $19 \times 19$ matrix where each element $m\left(e_{f}, e_{m}\right)$ describes the proportion of meetings of women with education $e_{f}$ and men with education $e_{m}$ in the economy. For each individual to meet one and only one person, this matrix should satisfy a set of $2 \times 19=38$ restrictions:

$$
\begin{aligned}
& \forall e_{m}: \sum_{e_{f}=1}^{19} m\left(e_{f}, e_{m}\right)=s^{m}\left(e_{m}\right), \\
& \forall e_{f}: \sum_{e_{m}=1}^{19} m\left(e_{f}, e_{m}\right)=s^{f}\left(e_{f}\right) .
\end{aligned}
$$

With random matching, we have

$$
m\left(e_{f}, e_{m}\right)=s^{f}\left(e_{f}\right) s^{m}\left(e_{m}\right),
$$

and the 38 constraints (B.1) and (B.2) are naturally satisfied by the fact that $\sum_{e_{f}} s^{f}\left(e_{f}\right)=1$ and $\sum_{e_{m}} s^{m}\left(e_{m}\right)=1$. 
TABLE B.1. Calibrated values of $\lambda$.

\begin{tabular}{lclclclc}
\hline Country & $\lambda$ & Country & $\lambda$ & Country & $\lambda$ & Country & $\lambda$ \\
\hline ALL & 0.125 & HTI & 0.108 & GHA & 0.058 & UGA & 0.088 \\
DHS & 0.098 & JAM & 0.088 & KEN & 0.110 & ZAF & 0.225 \\
ARG & 0.090 & MEX & 0.120 & LBR & 0.060 & ZMB & 0.088 \\
BOL & 0.098 & NIC & 0.128 & MAR & 0.100 & IDN & 0.163 \\
BRA & 0.150 & PAN & 0.138 & MLI & 0.110 & KHM & 0.098 \\
CHL & 0.118 & PER & 0.100 & MWI & 0.080 & THA & 0.138 \\
COL & 0.135 & SAL & 0.100 & RWA & 0.070 & VNM & 0.140 \\
CRI & 0.120 & URY & 0.138 & SEN & 0.100 & WBG & 0.070 \\
DOM & 0.090 & VEN & 0.160 & SLE & 0.078 & & \\
ECU & 0.110 & CAM & 0.118 & TZA & 0.115 & & \\
\hline
\end{tabular}

Assortative matching can be captured by the following assumption:

$$
m\left(e_{f}, e_{m}\right)=p\left(e_{f}\right) q\left(e_{m}\right) e^{-\lambda\left|e_{f}-e_{m}\right|} s^{f}\left(e_{f}\right) s^{m}\left(e_{m}\right) .
$$

The exponential term inflates the meeting probabilities when $i$ and $j$ are close. Parameter $\lambda$ parametrizes this inflation. The terms $p\left(e_{f}\right)$ and $q\left(e_{m}\right)$ are 38 scale factors that are introduced in order to satisfy (B.1) and (B.2). Without these terms, $m\left(e_{f}, e_{m}\right)=e^{-\lambda\left|e_{f}-e_{m}\right|} s^{f}\left(e_{f}\right) s^{m}\left(e_{m}\right)$, but (B.1) and (B.2) do not hold, implying that, in some education categories, there are individuals who do not meet anyone, whereas in some others, there are individuals who meet more than one partner.

When $\lambda=0$, we retrieve random matching, and the solution to (B.1) and (B.2) yields $p\left(e_{f}\right)=\vartheta$ and $q\left(e_{m}\right)=1 / \vartheta$, where $\vartheta$ is an arbitrary real number (a natural normalization is $p(1)=1$, implying $\vartheta=1$ ).

\section{B.2. Identification from SMM}

To illustrate how parameters are identified from the data, we show the effect of changing each parameter on the simulated moments for the total sample in Figures E.1- E.4 in the Online Appendix. For each figure, the top panel shows the marriage rates of females (left) and males (right), the middle panel shows the childlessness rates and completed fertility of mothers for married women, and the bottom panel shows the childlessness rates and completed fertility of mothers for single women. For each parameter change, we keep all the other variables fixed to their estimated values (third column in Table 3). For illustration purposes, we provide smaller or larger changes depending on which parameters we study.

Figure E.1 of the Online Appendix shows how a 7\% increase in $\phi$ and setting $\underline{\theta}=1$ (hence setting $\theta=1$ ) changes the simulated moments. The changes on the curves allow us to infer that $\underline{\theta}$ is identified from the concavity of the female marriage curve (top left panel). A higher $\underline{\theta}$ means a higher bargaining weight for the less educated person in a couple, who in the marriage market will then be rejected more often if low educated. This increases the number of poor women among the single and, hence, childlessness. Parameter $\phi$ is identified from the mean level of fertility of both single and married 
women, and from the increasing part of the relationship between childlessness and education.

Figure E. 2 of the Online Appendix shows the same exercise with $\delta_{f}$ and $\delta_{m}$. Here, we increase $\delta_{f}$ and $\delta_{m}$ by 0.1 . As already mentioned in the main text, both parameters are identified from the relationship between marriage rates and education. $\delta_{m}$ is identified from the slope of the relationship between male marriage rates and education (top right panel). A higher $\delta_{m}$ leads men to marry more, so that they will accept a match with a low-educated women more often, which allows the alleviation of social sterility. Similarly, $\delta_{f}$ is identified from the slope of the relationship between female marriage rates and education (top left panel).

Figure E. 3 of the Online Appendix shows the effect on the simulated moments of an increase of $26 \%$ for the mean of the nonlabor income $a_{i}$, of $0.27 \%$ for $\mu$, and of $7 \%$ for $v$. Parameter $v$ is identified from the increasing part of the U-shaped relationship between the childlessness of married women and education (an increase in $v$ makes children less valuable). Parameter $\mu$ is identified from the mean values of marriage rates: a higher $\mu$ increases the gains from marriage and hence the average marriage rate increases (top panel). The mean of the nonlabor income, $a_{i}$, is identified from the average fertility rate: a higher nonlabor income allows having more children, all else being equal.

From Figure E.4 of the Online Appendix, we can provide intuitions on the identification of $\hat{c}$ and $\alpha$. We increase $\hat{c}$ by $0.23 \%$ on average and set $\alpha$ to one in all countries. $\hat{c}$ is identified from the decreasing part of the U-shaped relationship between childlessness and the education of married women, and from the marriage rates of loweducated women. A larger $\hat{c}$ implies that more women will remain socially sterile and also that poor women are less attractive in the marriage market since the husband will have to use more of his income to allow her to have children. $\alpha$ is identified from the increasing part of the U-shaped relationship between childlessness and the education of married women, and the slope of the relationship between the completed fertility of married mothers and education (middle panels). In married couples, a larger $\alpha$ makes the opportunity cost of raising children more dependent on the wife's education, which is reflected in how fast fertility declines as the wife's education increases.

Figure E.5 of the Online Appendix shows how the aggregated simulated moments change when we increase $\varepsilon$ by $64 \%$ and the standard error of the distribution on the nonlabor income by $45 \%$. We can infer from the changes that a higher $\varepsilon$ is identified from the slope of the relationship between female marriage rates and education since men are more likely to marry low-educated women. The standard error of the nonlabor income is identified by the level of marriage rates; a higher standard error means that, within each category of education, individuals are less alike and therefore reject marriage offers more often.

\section{Appendix C: Details on the Calibration}

\section{C.1. Estimated Parameters for Each Country}




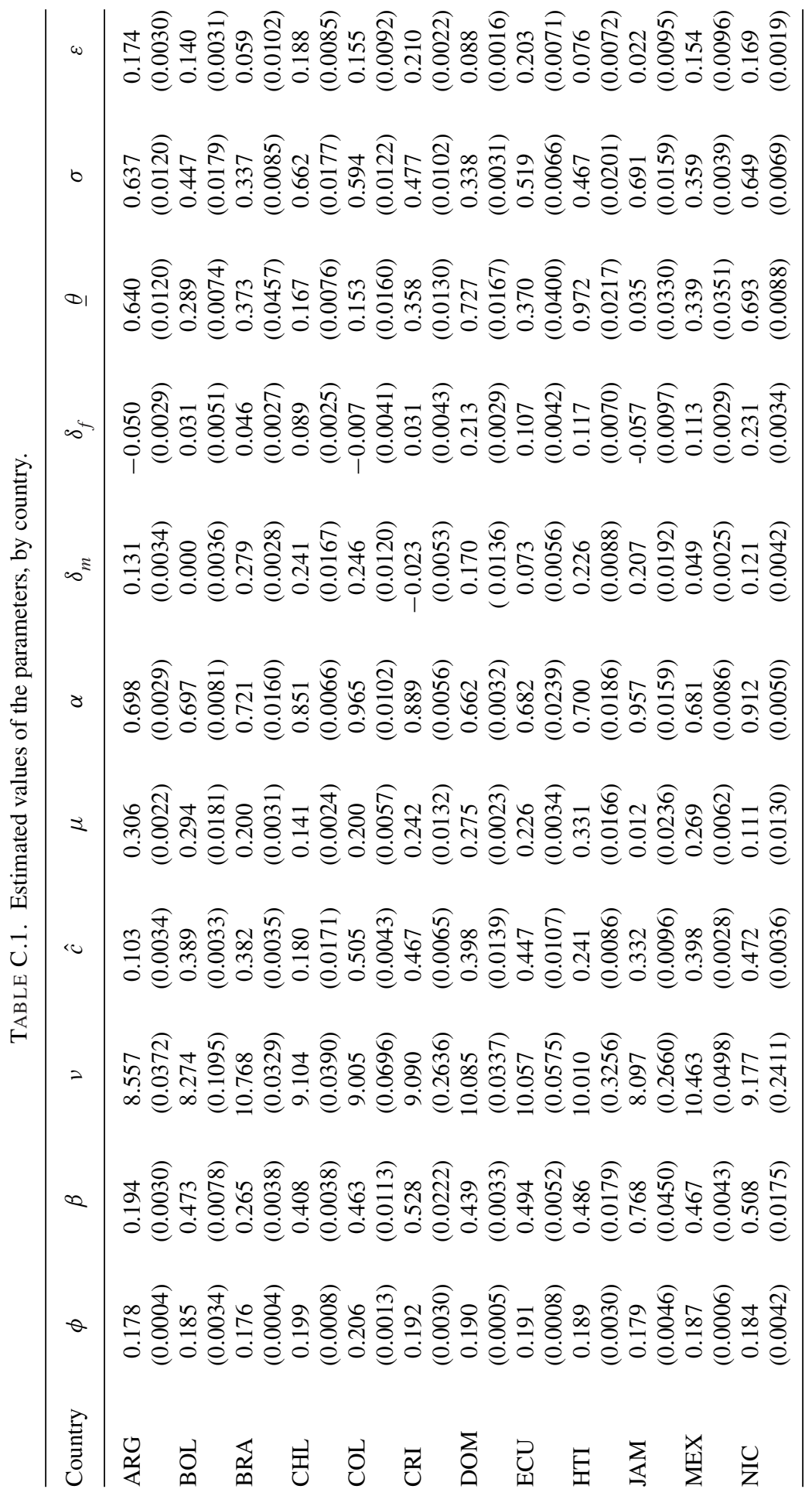




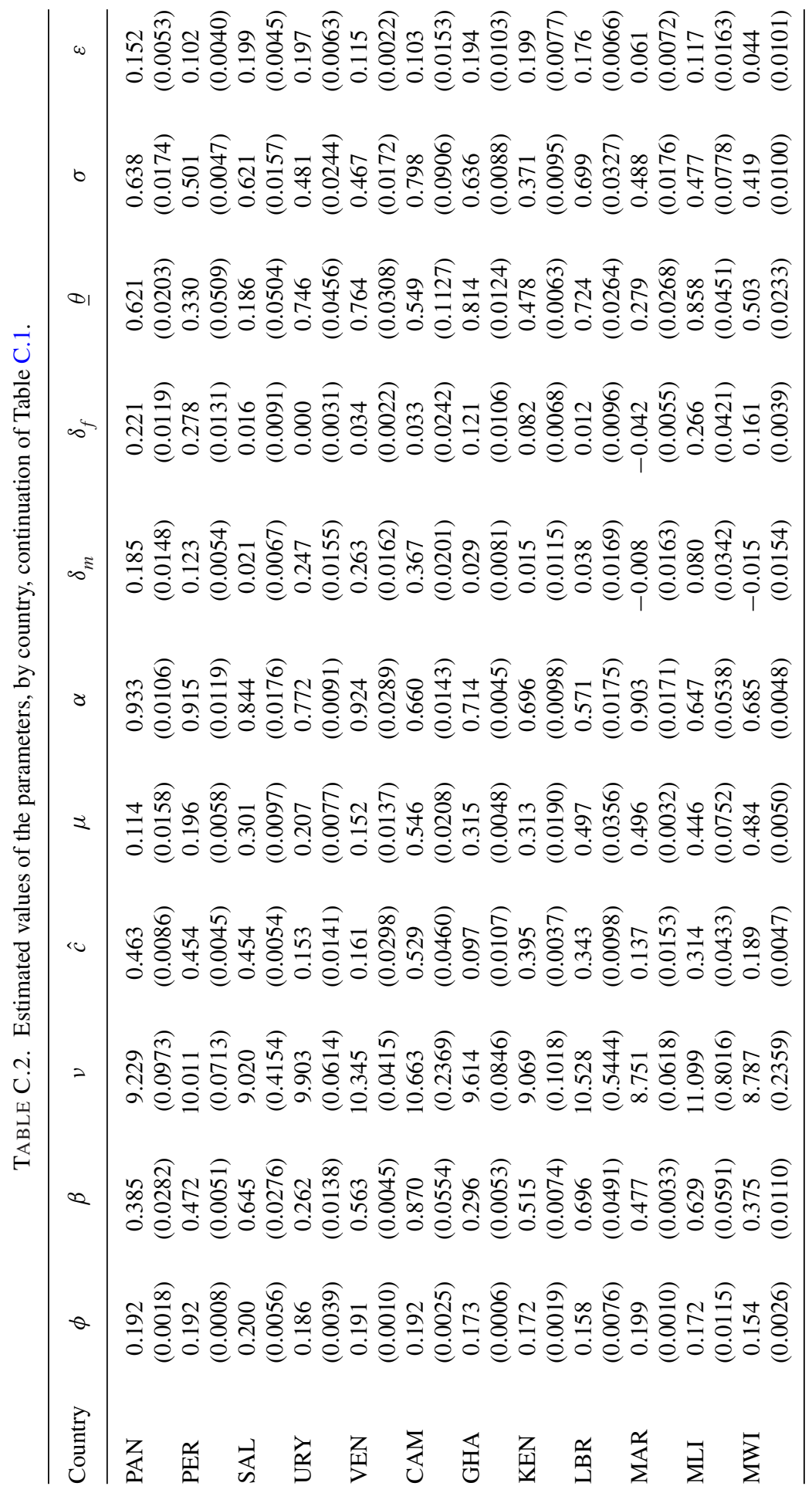




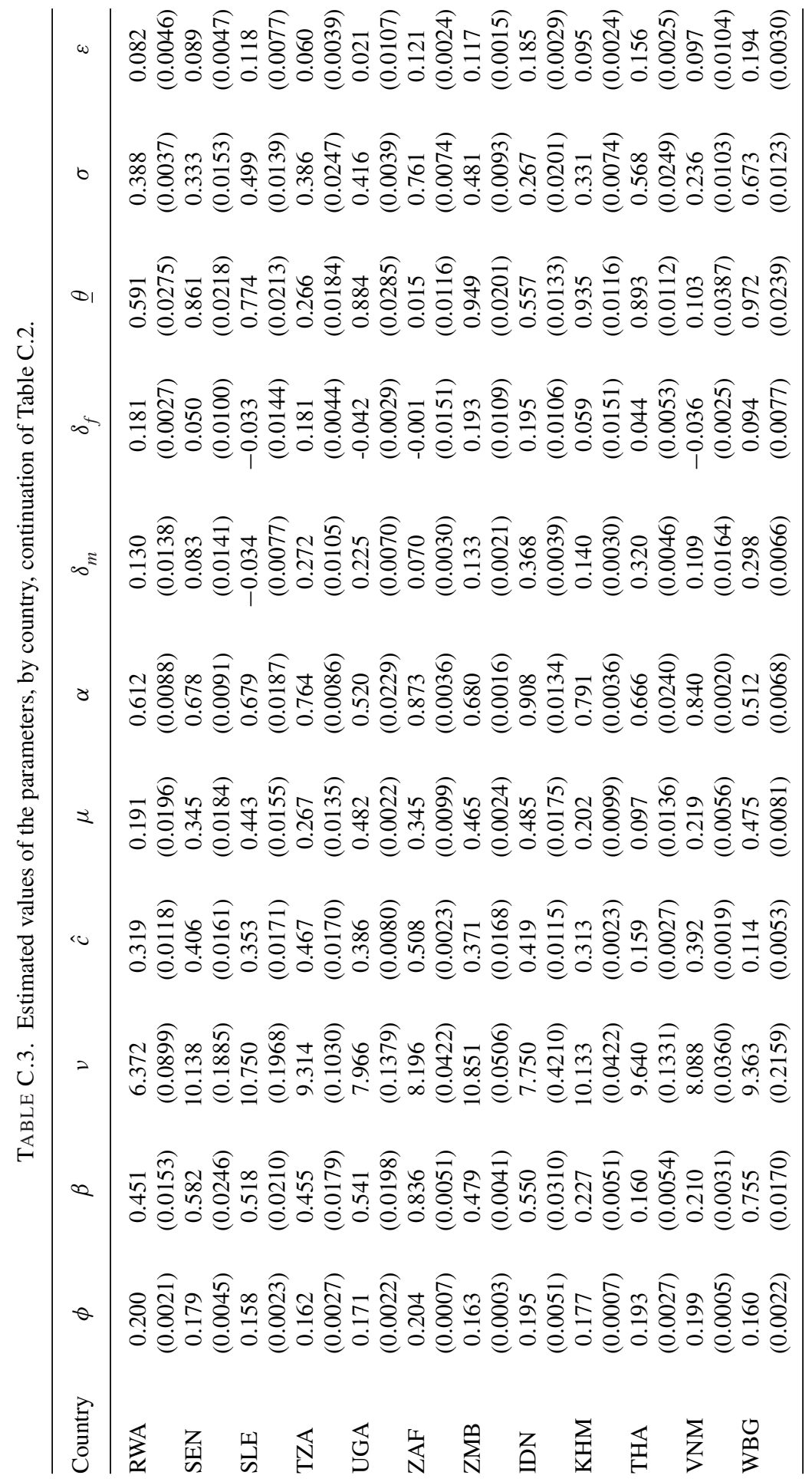




\section{C.2. Fit of the Structural Model to the Data}

C.2.1. Qualitative Fit of the Structural Model.
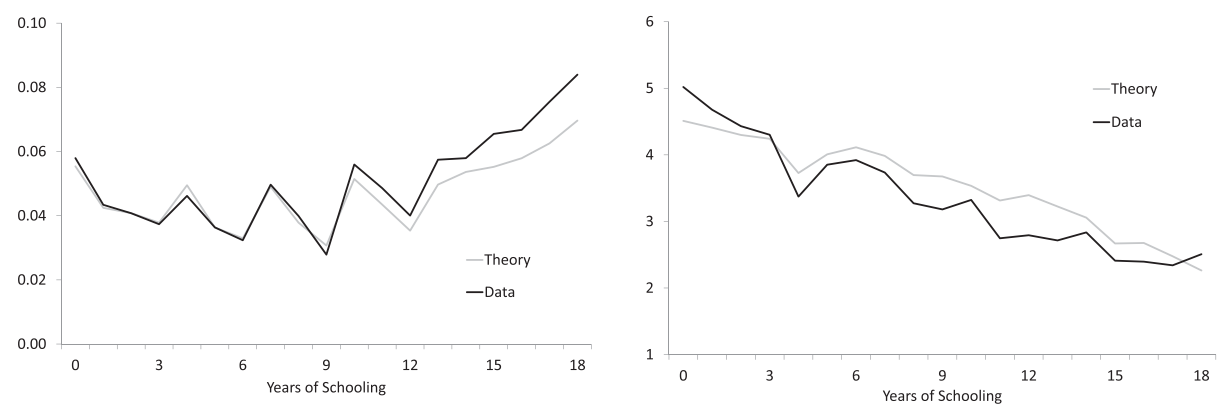

FIGURE C.1. Childlessness rate and completed fertility of mothers, married women.
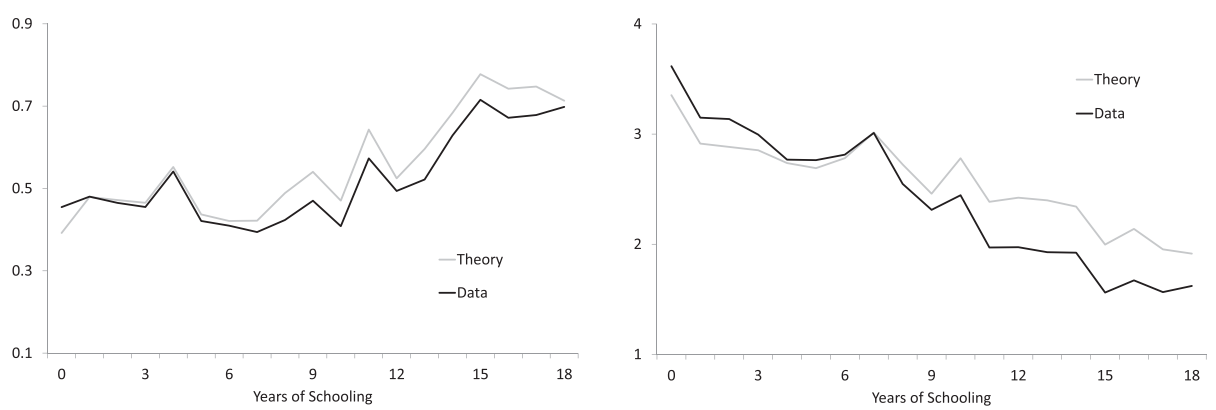

FIGURE C.2. Childlessness rate and completed fertility of mothers, single women.
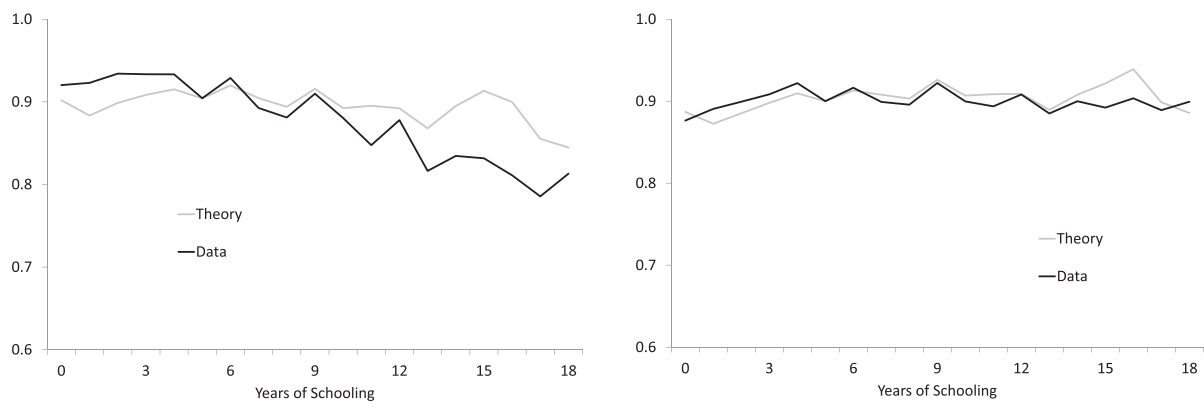

FIGURE C.3. Marriage rates of women (left) and men (right). 
C.2.2. Comparison with Ad Hoc Regressions. To go beyond qualitative statements about the quality of the fit of the structural model, we propose to compare the latter to that of an ad hoc linear regression model in which we regress our empirical moments on education and its square at the individual level. Let us consider the empirical moment "childlessness of married women" and denote $c_{i j}$ a dummy variable taking value one if a woman $i$ in country $j$ is childless and zero if she had at least one child. We compute the parameters of the following linear probability model in each country $j$ :

$$
c_{i j}=a_{1}^{j}+a_{2}^{j} e_{i j}+a_{3}^{j} e_{i j}^{2}+\varepsilon_{i j},
$$

where $\varepsilon_{i j}$ is supposed to follow a normal distribution with zero mean and constant variance. From that regression, we predict for all married women in our sample a probability of being childless at the end of their reproductive life. Using the weights provided by IPUMS (used to compute our empirical moments), we generate the childlessness rates predicted by the ad hoc model for each education category. This ad-hoc model is endowed with $3 \times 36=108$ parameters. Not surprisingly, the fit of this model is almost perfect. We repeat this process for the childlessness rate of single women, female and male marriage rates, as well as the fertility of single and married mothers (OLS regression in this last case). At the end, we have used $108 \times 6=648$ parameters to obtain an almost perfect fit.

In our structural approach, after fixing some parameters a priori, we use $11 \times$ $36=396$ parameters to minimize the distance between our empirical and simulated moments. We also impose 288 restrictions on the value of the estimated parameters since in each country, all the elements of the vector $(\hat{c}, \beta, \sigma, v, \mu)$ have to be positive whereas those of the vector $(\phi, \alpha, \underline{\theta} / 2)$ have to belong to $[0,1]$. With the $a d$ hocregression model, $f(p)$ from equation (10) is equal to 0.0701 , whereas $f(p)=$ 1.1569 using our structural estimation model.

To make things more intuitive, we build the following statistics denoted $\mathcal{F}$ :

$$
\mathcal{F}=\frac{1}{114} \sum_{m=1}^{114}\left|\frac{f_{e}(m)-f_{t}(m)}{f_{e}(m)}\right|
$$

where 114 is the number of aggregated moments we finally try to reproduce. $f_{e}(m)$ and $f_{t}(m)$ respectively denote the empirical and predicted values of moment $m$ at the aggregate level. With the ad hoc regression model, $\mathcal{F}=0.0168$ whereas $\mathcal{F}=0.0611$ with the structural estimation model. It means that, on average, for any moment we try to reproduce, the distance between the value predicted by the ad hoc model and its empirical value represents $1.68 \%$ of the empirical value. In the case of the structural model, the error represents on average $6.11 \%$ of its empirical counterpart. The difference between these two values is the cost to pay in order to be able to decompose childlessness into its four components and to estimate the relationship between fertility, childlessness, and development. We tend to think that this cost remains quite reasonable since for instance, as shown in Figure 6, our model is able to explain more than $97 \%$ of childlessness at the aggregate level. 
As for many measures of fit, one may want to correct the proposed measure thanks to a criterion of parsimony. In the spirit of an adjusted $R^{2}$, we have computed

$$
\mathcal{F}_{\text {Adj }}=\frac{n-1}{n-p-1} \times \mathcal{F},
$$

where $n$ is the number of country-specific moments to be reproduced by each model. $n$ is equal to 4,104 , corresponding to 6 moments for each of the 19 education categories in our 36 countries. $p$ denotes the number of parameters used by our two alternative models. We obtain $\mathcal{F}_{A d j}=0.0199$ in the case of ad hoc regressions and $\mathcal{F}_{A d j}=0.0676$ in the case of structural estimations. The correction is rather limited.

\section{C.3. Intercountry Variability of Estimated Parameters}

Can we explain the variability of our estimates using measurable factors that differ across countries? We estimate the relationship between our estimated values of parameters $\hat{c}, \alpha$, and $\underline{\theta}$, and the deep-rooted factors in comparative economic development stressed by the literature:

$$
p_{j}=a_{0}+a_{1} \text { European Settlers }_{j}+a_{2} \text { Matrilocal }_{j}+a_{3} \text { Patrilocal }_{j}+X_{j}+\varepsilon_{j}
$$

where subscript $j$ denotes a country. $p$ denotes the estimated value of the parameter from Section 4.2. There are three main explanatory variables. As most of the countries studied have been colonies of European countries, the first explanatory variable, "European Settlers", measures the percentage of the population that was European or from European descent by 1900. These data come from Acemoglu et al. (2002). As in Acemoglu et al. (2002), we use the proportion of European settlers in the population as a proxy for the current quality of institutions. The second and third variables, "Matrilocal" and "Patrilocal", respectively measure the proportion of a country's ancestors with matrilocal and patrilocal postmarital residence rules. These data are taken from Alesina et al. (2013).

$X$ denotes the control variables, which include: continental dummies, the share of individuals who are Catholic and Muslim in the population from Alesina et al. (2013), a dummy variable that takes the value one for the countries for which we do not have information on the fertility of single women and zero otherwise, the GDP per capita for the year of the census considered expressed in PPP current dollars (data from World Bank), and the logarithm of the mortality rates of soldiers, bishops, and sailors living in the colonies between the 17th and 19th centuries, from Acemoglu et al. (2002). We use this last control variable, the mortality rate of settlers, as a way to measure reproductive conditions in the past. It may be the case that environments where mortality was very high two centuries ago have imposed a natural selection, allowing only the fittest women to reproduce. ${ }^{41}$

41. The use of the variable measuring the log-mortality of settlers should be taken with caution as these data have been strongly criticized by Albouy (2012). 
TABLE C.4. Deep roots of $\hat{c}, \alpha$, and $\underline{\theta}$.

\begin{tabular}{lccc}
\hline & \multicolumn{3}{c}{ Dependent variable } \\
\cline { 2 - 4 } & $\hat{c}$ & $\alpha$ & $\underline{\theta}$ \\
\hline European settlers & $-0.004^{* *}$ & -0.002 & 0.004 \\
Matrilocal & $(0.002)$ & $(0.002)$ & $(0.003)$ \\
& 0.107 & $0.285^{* *}$ & -0.084 \\
Patrilocal & $(0.133)$ & $(0.108)$ & $(0.232)$ \\
& 0.115 & 0.009 & $-0.487^{* * *}$ \\
Controls & $(0.079)$ & $(0.064)$ & $(0.137)$ \\
Religion & YES & YES & YES \\
Continental dummies & YES & YES & YES \\
Observations & YES & YES & 33 \\
$R$-squared & 33 & 33 & 0.593 \\
Adjusted $R^{2}$ & 0.386 & 0.484 & 0.408 \\
\hline
\end{tabular}

Notes: Standard errors in parentheses. ${ }^{* *} p<0.05 ;{ }^{* * *} p<0.01$.

Table C. 4 shows the results of estimating equation (C.1) by OLS. The first column of the estimated coefficients shows the results when the dependent variable is $\hat{c}$. We find a significant negative association between the percentage of the population that was European and the minimum consumption threshold that allows a woman to have a child. This result suggests that in places where Europeans settled most, which in our case is true for Argentina, Chile, and Uruguay, they promoted better institutions, which tend to reduce the value of the threshold level of $\hat{c}$. Notice that this effect goes beyond an effect of GDP per capita, as we control for the latter.

The second column shows the estimates of the coefficients in equation (C.1) when the dependent variable is $\alpha$. This parameter is positively associated to the proportion of ancestors with matrilocal postmarital residence rules. Such past rules of location after marriage thus seem to have contributed to a social norm implying a high time share supplied by women in rearing children. For instance, Nicaragua, Panama, and Venezuela, both have a high prevalence of matrilocal roots and a high share of time supplied by women.

The last column shows the results when the dependent variable is the estimates for $\underline{\theta}$. In our theoretical model, $\underline{\theta}$ denotes the bounds of spouses' negotiation power within marriage. The higher $\underline{\theta}$, the less marriage surplus the spouse with the higher wage can extract. This parameter should then also correlate to variables describing the functioning of marriage institutions. We find that countries where the estimates for $\underline{\theta}$ are high have a smaller share of the population that respects patrilocal location rules after marriage. This suggests that the prevalence of patrilocal rules seems to have durably opened the possibility for men (who are more often those who earn more in our dataset) of extracting more surplus from marriage. Countries in which patrilocal rules seem to matter for the low values of $\underline{\theta}$ are for instance Jamaica and Morocco.

Finally, a word of caution. In all that precedes, the number of observations is small, implying that all the statistical tests have low power. 


\section{Appendix D: Robustness Analysis}

In this appendix, we study the robustness of our analysis to some major changes in assumptions. In each case, we reestimate the parameters under the new assumption and redo the comparative statics of Section 5.2. We first study robustness to the choice of the Mincerian return $\rho$. Instead of using a rate of return of education of $5 \%$ in all countries, we take the country specific returns rates collected in Montenegro and Patrinos (2014). Second, we look at the robustness to the assumption on marriage. In the main text, we assume that both spouses have to agree to marry for a marriage to take place (see equation (8)). Here we assume a more sexist society where only the consent of the groom is needed. Third, we compare the results to the case where the matching in the marriage market is random. Finally, we change the measure of unwanted births, assuming that a woman does not control fertility if she had one more child than her declared ideal and she believes her husband did not want more children than her (measure 6 of Table A.2).

\section{D.1. Higher Returns to Education}

Table D.1 displays the Mincerian return to schooling from Montenegro and Patrinos (2014) together with the year for which they are estimated. The results obtained under this alternative way of measuring $\rho$ are compared to the benchmark result in Table D.2. With the new $\rho$ the people with low education are much poorer relatively to the highly educated ones: indeed the wage for a woman with no education is now 0.10 instead of 0.31 (remember that the wage of the highest degree of education for men is normalized

TABLE D.1. Different values of the return to schooling $\rho$ for given years.

\begin{tabular}{lrllrl}
\hline & $\rho$ & Year & & $\rho$ & Year \\
\hline ARG & 7.8 & 1992 & GHA & 12.5 & 2012 \\
BOL & 10.4 & 2001 & KEN & 16.9 & 2005 \\
BRA & 14.3 & 2001 & LBR & $12.4^{\mathrm{a}}$ & \\
CHL & 13.2 & 2003 & MAR & 10.0 & 1998 \\
COL & 11.3 & 2005 & MLI & 13.0 & 1994 \\
CRI & 9.3 & 2000 & MWI & 9.8 & 2010 \\
DOM & 9.5 & 2010 & RWA & 17.5 & 2005 \\
ECU & 7.8 & 2010 & SEN & 11.8 & 2011 \\
HTI & 8.3 & 2001 & SLE & 4.2 & 2003 \\
JAM & 11.1 & 2001 & TZA & 15.2 & 2000 \\
MEX & 10.1 & 2010 & UGA & 16.9 & 2005 \\
NIC & 7.7 & 2005 & ZAF & 16.5 & 2001 \\
PAN & 10.0 & 2010 & ZMB & 12.6 & 2010 \\
PER & 10.6 & 2007 & IDN & 12.1 & 1998 \\
SAL & 8.4 & 2007 & KHM & 4.3 & 2008 \\
URY & 10.9 & 1996 & THA & 16.0 & 2000 \\
VEN & 9.2 & 2001 & VNM & $9.4^{\mathrm{a}}$ & \\
CAM & 11.6 & 2007 & WBG & 1.4 & 1998 \\
\hline
\end{tabular}

Note: a. Value for the region (Table 3a in Montenegro and Patrinos 2014). 
TABLE D.2. Results under different assumptions for all countries aggregated.

\begin{tabular}{|c|c|c|c|c|c|}
\hline & Benchmark & Higher $\rho$ & $\begin{array}{c}\text { Sexist } \\
\text { marriage }\end{array}$ & $\begin{array}{c}\text { Random } \\
\text { match }\end{array}$ & $\kappa^{\prime}$ \\
\hline \multicolumn{6}{|c|}{ Parameters-mean over countries } \\
\hline$\beta$ & 0.477 & 0.464 & 0.554 & 0.471 & 0.449 \\
\hline$\sigma$ & 0.506 & 0.090 & 0.118 & 0.092 & 0.519 \\
\hline$v$ & 9.518 & 8.999 & 8.539 & 8.060 & 9.427 \\
\hline$\hat{c}$ & 0.342 & 0.212 & 0.276 & 0.264 & 0.319 \\
\hline$\mu$ & 0.302 & 0.252 & 0.240 & 0.241 & 0.291 \\
\hline$\alpha$ & 0.754 & 0.786 & 0.786 & 0.830 & 0.759 \\
\hline$\phi$ & 0.184 & 0.188 & 0.178 & 0.190 & 0.182 \\
\hline$\delta^{m}$ & 0.141 & 0.141 & 0.202 & 0.131 & 0.132 \\
\hline$\delta^{f}$ & 0.080 & 0.161 & 0.029 & 0.196 & 0.074 \\
\hline$\underline{\theta}$ & 0.545 & 0.701 & 0.614 & 0.693 & 0.537 \\
\hline$\varepsilon$ & 0.125 & 0.080 & 0.074 & 0.080 & 0.106 \\
\hline$\rho$ & 0.050 & 0.111 & 0.050 & 0.050 & 0.050 \\
\hline$\lambda$ & 0.111 & 0.111 & 0.111 & 0 & 0.111 \\
\hline$f(p)$-average & 1.943 & 2.355 & 25.113 & 3.002 & 1.832 \\
\hline$R^{2}$ & 0.971 & 0.973 & 0.393 & 0.914 & 0.758 \\
\hline \multicolumn{6}{|c|}{ Development and Childlessness } \\
\hline$\partial$ opp.-driven/ $\partial$ schooling & 0.67 & 0.52 & 0.40 & 0.51 & 0.47 \\
\hline$\partial$ pov.-driven/ $\partial$ schooling & -0.68 & -0.64 & -0.52 & -0.57 & -0.40 \\
\hline \multicolumn{6}{|c|}{ Decomposition of childlessness (ALL) } \\
\hline Opp.-driven & 3.5 & 2.4 & 4.7 & 2.4 & 3.6 \\
\hline Poverty-driven & 2.3 & 3.6 & 1.3 & 3.5 & 2.9 \\
\hline Mortality-driven & 0.5 & 0.2 & 0.5 & 0.1 & 0.6 \\
\hline Natural sterility & 1.9 & 1.9 & 1.9 & 1.9 & 1.9 \\
\hline \multicolumn{6}{|l|}{ Comparative Statics } \\
\hline Education $\Delta \mathrm{F} / \mathrm{F}$ & -1.56 & 0.44 & -1.71 & -1.33 & -1.91 \\
\hline Education $\Delta \mathrm{F}_{\mathrm{p}} / \mathrm{F}$ & -3.02 & -1.48 & -2.82 & -3.08 & -3.15 \\
\hline Planning $\Delta \mathrm{F} / \mathrm{F}$ & -16.40 & -8.81 & -16.23 & -16.49 & -16.50 \\
\hline Planning $\Delta \mathrm{F}_{\mathrm{p}} / \mathrm{F}$ & -16.92 & -8.82 & -16.53 & -16.93 & -16.81 \\
\hline Health $\Delta \mathrm{F} / \mathrm{F}$ & 5.03 & 7.50 & 5.02 & 5.27 & 4.75 \\
\hline Health $\Delta \mathrm{F}_{\mathrm{p}} / \mathrm{F}$ & 6.06 & 7.39 & 6.05 & 6.17 & 5.39 \\
\hline Empowerment $\Delta \mathrm{F} / \mathrm{F}$ & -12.97 & -7.35 & -10.05 & -12.92 & -14.99 \\
\hline Empowerment $\Delta \mathrm{F}_{\mathrm{p}} / \mathrm{F}$ & -8.21 & -5.34 & -8.36 & -7.49 & -9.52 \\
\hline
\end{tabular}

to one). As a consequence, the parameters measuring good costs, $\mu$ and $\hat{c}$, are lower. The higher value of $\rho$ also modifies the incentives to accept a marriage offer. In particular, it makes highly educated women less willing to match with lowly educated men. To counterbalance this effect, the estimated $\delta^{f}$ is higher, making singleness more painful to educated women.

Concerning the fit of the model, we report the average value of the minimized objective function $f(p)$ for all countries, and the $R^{2}$ of the fit of childlessness across countries (regression in Figure 6). We see that with the new value of $\rho$ the global fit is worse, but that cross-country childlessness is still matched as well as before. 
The way development affects childlessness is not altered by the new estimation, as the slopes of the relationship between opportunity-driven childlessness and education (bottom panel of Figure 7) and between poverty-driven childlessness and education (top panel of Figure 7) are almost unchanged. Moreover, the decomposition of childlessness is mildly modified, with more poverty-driven childlessness with the higher $\rho$.

Finally, considering the comparative statics, the results from Section 5.2 still hold. The effect of education on fertility is reversed by accounting for all margins. It remains true that neglecting the endogenous response of marriage and childlessness has a negligible effect on the impact of better family planning and that it leads to underestimating the effect of promoting gender equality on fertility. However, the impact of lower mortality on fertility is not affected by neglecting the extensive margin and the marriage response under the assumption of higher values of $\rho$.

\section{D.2. Sexist Society}

The second robustness exercise replaces the assumption that a match on the marriage market will end up married only if both partners are willing:

$$
\mathcal{M}_{f}\left(e_{f}, a_{f}, e_{m}, a_{m}\right) \geq \mathcal{S}\left(e_{f}, a_{f}\right) \quad \text { and } \quad \mathcal{M}_{m}\left(e_{m}, a_{m}, e_{f}, a_{f}\right) \geq \mathcal{S}\left(e_{m}, a_{m}\right),
$$

by the assumption that a match will end up married only if the man is willing:

$$
\mathcal{M}_{m}\left(e_{m}, a_{m}, e_{f}, a_{f}\right) \geq \mathcal{S}\left(e_{m}, a_{m}\right) .
$$

This change of assumption has major consequences on the estimation. In the benchmark, the population of single women was composed of poor women who were denied marriage, and rich women who refused marriage. Now, only the first category subsists.

Despite the fact that we reestimate the parameters under the new assumption, the fit of this version of the model is awful. The property that poverty-driven childlessness decreases, and opportunity-driven childlessness increases with development is kept, whereas the decomposition of childlessness leads to a higher estimate for the opportunity-driven component. The comparative static exercises lead however to quite comparable results.

We conclude that assuming a sexist society by just disregarding the interest of women in marriage is a bad assumption. In societies where the bride has no say, it might remain true that her interest is somewhat taken into account by her father, as in Doepke and Tertilt (2009).

\section{D.3. Random Matching}

The benchmark model assumes assortative matching, along education levels. Alternatively, here for each woman in each category of education, we draw a potential husband from the empirical distribution of education levels among men.

Results are presented in the column "random matching" of Table D.2. The fit of the model deteriorates a little but all the results remain valid with this assumption. 
The estimates of opportunity-driven childlessness decreases and that of poverty-driven childlessness increases, as more poor women will be rejected from the marriage market under this assumption. The results on whether including the endogenous responses of marriage and childlessness matters for the comparative statics remain all valid and qualitatively the same to the benchmark.

\section{D.4. Alternative Measure of Unwanted Birth}

The last column in Table D.2 shows the robustness of the results when changing the measure of unwanted births. We now assume that a woman does not control fertility if she had one more child than her declared ideal and she believes her husband did not want more children than her. The new probabilities not to control fertility are denoted by $\kappa^{\prime}$.

Again, the results are robust to changing the measure of unwanted birth. The quality of the fit is not altered as well as the decomposition of childlessness. One direct interpretation of this result is that, if measure 6 corrects for the ex post rationalization bias, this latter had no impact on our estimation. The main change is that now the effect of family planning on fertility is amplified, both when accounting for the endogeneity of marriage and childlessness and when not, this result mainly due to a weighting phenomenon.

\section{References}

Aaronson, Daniel, Fabian Lange, and Bhashkar Mazumder (2014). "Fertility Transitions along the Extensive and Intensive Margins." American Economic Review, 104(11), 3701-3724.

Acemoglu, Daron, Simon Johnson, and James Robinson (2002). "Reversal of Fortune: Geography and Institutions in the Making of the Modern World Income Distribution." The Quarterly Journal of Economics, 117, 1231-1294.

Albouy, David Y. (2012). "The Colonial Origins of Comparative Development: An Empirical Investigation: Comment.” American Economic Review, 102(6), 3059-3076.

Alesina, Alberto, Paola Giuliano, and Nathan Nunn (2013). "On the Origins of Gender Roles: Women and the Plough." The Quarterly Journal of Economics, 128, 469-530.

Ashraf, Nava, Erica Field, and Jean Lee (2014). "Household Bargaining and Excess Fertility: An Experimental Study in Zambia." American Economic Review, 104(7), 2210-2237.

Baudin, Thomas (2012). "The Optimal Trade-Off Between Quality and Quantity with Unknown Number of Survivors." Mathematical Population Studies, 19, 94-113.

Baudin, Thomas and Paula E. Gobbi (2016). "Family Planning is Not (Necessarily) the Priority Institution for Reducing Fertility." In Institutions for Future Generations, edited by Axel Gosseries and Iñigo González-Ricoy. Oxford University Press.

Baudin, Thomas, David de la Croix, and Paula E. Gobbi (2015). "Fertility and Childlessness in the US.” American Economic Review, 105(6), 1852-1882.

Belsey, Mark A. (1976). "The Epidemiology of Infertility: A Review with Particular Reference to Sub-Saharan Africa." Bulletin of World Health Organization, 54, 319-341.

Bhattacharya, Joydeep and Shankha Chakraborty (2017). "Contraception and the Fertility Transition." The Economic Journal, 127, 2263-2301.

Bongaarts, J. (1994a) . "Population Policy Options in the Developing World." Science, 263, 771-776.

Bongaarts, J. and J. Casterline (2013). "Fertility Transition: Is Sub-Saharan Africa Different?" Population and Development Review, 38, 153-168. 
Bongaarts, John (1994b). "The Impact of Population Policies: Comment." Population and Development Review, 20, 616-620.

Charbonneau, Paul (1995). "Genetic Algorithms in Astronomy and Astrophysics." The Astrophysical Journal Supplement Series, 101, 309.

Chiappori, Pierre André (1988). "Rational Household Labor Supply." Econometrica, 56, 63-90.

Cleland, John, Mohamed M. Ali, and Iqbal Shah (2006). "Trends in Protective Behaviour among Single Vs. Married Young Women in Sub-Saharan Africa: The Big Picture." Reproductive Health Matters, 14, 17-22.

de la Croix David and Fabio Mariani (2015). "From Polygyny to Serial Monogamy: A Unified Theory of Marriage Institutions." Review of Economic Studies, 82, 565-607.

de la Croix David and Marie Vander Donckt (2010). "Would Empowering Women Initiate the Demographic Transition in Least Developed Countries?" Journal of Human Capital, 4, 85-129.

Doepke, Matthias and Michèle Tertilt (2009). "Women's Liberation: What's in It for Men?" The Quarterly Journal of Economics, 124, 1541-1591.

Ezeh, A. C., J. Bongaarts, and B. Mberu (2012). "Global Population Trends and Policy Options." The Lancet, 380, 142-148.

Fernández-Villaverde, Jesús, Jeremy Greenwood, and Nezih Guner (2014). "From Shame to Game in One Hundred Years: An Economic Model of the Rise in Premarital Sex and Its De-Stigmatization." Journal of the European Economic Association, 12, 25-61.

Frank, Odile (1983). "Infertility in Sub-Saharan Africa: Estimates and Implications." Population and Development Review, 9, 137-144.

Gobbi, Paula E. (2013). "A Model of Voluntary Childlessness." Journal of Population Economics, 26, 963-982.

Gobbi, Paula E. (2018). "Childcare and Commitment within Households." Journal of Economic Theory, 176, 503-551.

Greenwood, Jeremy, Nezih Guner, Georgi Kocharkov, and Cezar Santos (2014). "Marry Your Like: Assortative Mating and Income Inequality.” American Economic Review, 104(5), 348-353.

Greenwood, Jeremy, Nezih Guner, Georgi Kocharkov, and Cezar Santos (2016). "Technology and the Changing Family: A Unified Model of Marriage, Divorce, Educational Attainment and Married Female Labor-Force Participation.” AEJ: Macroecroeconomics, 8, 1-41.

Hausmann, Ricardo, Laura D. Tyson, Yasmina Bekhouche, and Saadia Zahidi (2013). The Global Gender Gap Report 2013. World Economic Forum.

Lesthaeghe, Ron (2015). The Decline of Belgian Fertility, 1800-1970. Princeton University Press, Princeton.

Leukhina, Oksana and Michael Bar (2010). "Demographic Transition and Industrial Revolution: A Macroeconomic Investigation." Review of Economic Dynamics, 13, 424-451.

Malthus, Thomas (1798). An Essay on the Principle of Population. Johnson, London.

May, John (2012). World Population Policies: Their Origin, Evolution, and Impact. Springer.

McFalls, Joseph A. (1979). "Frustrated Fertility: A Population Paradox." Population Bulletin, 34, 3-43.

Montenegro, Claudio E. and Harry Anthony Patrinos (2014). "Comparable Estimates of Returns to Schooling around the World." Policy Research Working Paper Series 7020.

Olwen, Hufton (1984). "Women Without Men: Widows and Spinsters in Britain and France in the Eighteenth Century." Journal of Family History, 9, 355-376.

Ombelet, Willem, Ian Cooke, Silke Dyer, Gamal Serour, and Paul Devroey (2008). "Infertility and the Provision of Infertility Medical Services in Developing Countries." Human Reproduction Update, 14, 605-621.

Oyelere, Ruth Uwaifo (2008). "Economic and Econometric Evidence for and against Private Income and Employment Benefits of Education in Africa." Department of Economics, Georgia Institute of Technology.

Poston, Dudley L., Jr, Elizabeth Briody, Katherine Trent, and Harley L. Browning (1985). "Modernization and Childlessness in the States of Mexico." Economic Development and Cultural Change, 34, 503-519.

Poston, Dudley L. and Katherine Trent (1982). "International Variability in Childlessness: A Descriptive and Analytical Study." Journal of Family Issues, 3, 473-491. 
Pritchett, Lant H. (1994a). "Desired Fertility and the Impact of Population Policies." Population and Development Review, 20, 1-55.

Pritchett, Lant H. (1994b). "The Impact of Population Policies: Reply.” Population and Development Review, 20, 621-630.

Retel-Laurentin, Anne (1974). Infécondité en Afrique noire: Maladies et Conséquences Sociales. Masson.

Roberts, George W. (1957). The Population of Jamaica. Cambridge University Press, Cambridge, MA.

Romaniuk, Anatole (1980). "Increase in Natural Fertility During the Early Stages of Modernization: Evidence from an African Case Study, Zaire.” Population Studies, 34, 293-310.

Ruggles, Steven, Robert McCaa, Matthew Sobek, and Lara Cleveland (2015). "The IPUMS Collaboration: Integrating and Disseminating the World's Population Microdata." Journal of Demographic Economics, 81, 203-216.

Sah, Raaj K. (1991). "The Effect of Child Mortality Changes on Fertility Choice and Parental Welfare." Journal of Political Economy, 99, 582-606.

Schoumaker, Bruno (2009). Stalls in Fertility Transitions in Sub-Saharan Africa: Real or Spurious? Département des Sciences de la Population et du Développement, Université catholique de Louvain.

Sen, Amartya K. and Martha Nussbaum (1993). “Capability and Well-Being.” In The Quality of Life. Clarendon Press, Oxford, pp. 30-53.

Tietze, Sara L. (1957). "Reproductive Span and Rate of Reproduction among Hutterite Women." Fertility and Sterility, 8, 89-97.

Vogl, Tom (2016). "Differential Fertility, Human Capital, and Development." Review of Economic Studies, 83, 365-401.

Wolowyna, Jean E. (1977). "Income and Childlessness in Canada: A Further Examination." Social Biology, 24, 326-331.

\section{Supplementary Data}

Supplementary data are available at JEEA online. 